\title{
Sex-regulated gene dosage effect of PPARa on synaptic plasticity
}

\author{
Nathalie Pierrot ${ }^{1,2} \mathbb{D}$, Laurence Ris ${ }^{3}$, Ilie-Cosmin Stancu ${ }^{1,2,4} \mathbb{\oplus}$, Anna Doshina ${ }^{1,2}$, Floriane Ribeiro ${ }^{1,2}$, Donatienne Tyteca ${ }^{1,5}$, \\ Eric Baugé ${ }^{6}$, Fanny Lalloyer ${ }^{6}$, Liza Malong ${ }^{1,2} \mathbb{\infty}$, Olivier Schakman ${ }^{1,2}$, Karelle Leroy ${ }^{7}$, Pascal Kienlen-Campard ${ }^{1,2} \mathbb{D}^{\mathbb{D}}$, \\ Philippe Gailly, ${ }^{1,2}$, Jean-Pierre Brion ${ }^{7} \mathbb{B}$, Ilse Dewachter ${ }^{1,2,4}$, Bart Staels ${ }^{6}$, Jean-Noël Octave ${ }^{1,2}$
}

\begin{abstract}
Mechanisms driving cognitive improvements following nuclear receptor activation are poorly understood. The peroxisome proliferator-activated nuclear receptor alpha (PPAR $\alpha$ ) forms heterodimers with the nuclear retinoid $X$ receptor (RXR). We report that PPAR $\alpha$ mediates the improvement of hippocampal synaptic plasticity upon RXR activation in a transgenic mouse model with cognitive deficits. This improvement results from an increase in GluA1 subunit expression of the alpha-amino-3hydroxy-5-methyl-4-isoxazolepropionic acid (AMPA) receptor, eliciting an AMPA response at the excitatory synapses. Associated with a two times higher PPAR $\alpha$ expression in males than in females, we show that male, but not female, PPAR $\alpha$ null mutants display impaired hippocampal long-term potentiation. Moreover, PPARa knockdown in the hippocampus of cognition-impaired mice compromises the beneficial effects of RXR activation on synaptic plasticity only in males. Furthermore, selective PPAR $\alpha$ activation with pemafibrate improves synaptic plasticity in male cognition-impaired mice, but not in females. We conclude that striking sex differences in hippocampal synaptic plasticity are observed in mice, related to differences in PPARa expression levels.
\end{abstract}

DOI 10.26508/lsa.201800262 | Received 30 November 2018 | Revised 1 March 2019 | Accepted 11 March 2019 | Published online 20 March 2019

\section{Introduction}

The nuclear receptor (NR) superfamily of ligand-dependent transcription factors are broadly implicated in a wide variety of biological processes regulating energy balance, inflammation, lipid, and glucose metabolism (Evans \& Mangelsdorf, 2014). NRs play an important role in the adaptive responses to environmental changes by controlling directly the expression of target genes through binding to sequence-specific elements located in gene regulatory regions (Evans \& Mangelsdorf, 2014). Among NRs, peroxisome proliferator-activated receptors (PPARs) and the liver $X$ receptors (LXRs) form obligate heterodimers with retinoid $X$ receptors (RXRS). PPAR/RXR and LXR/RXR heterodimers are permissive, meaning that receptor dimers can be activated by ligands for either partner in the dimer, or even by both synergistically (Evans \& Mangelsdorf, 2014).

PPARs, including PPAR $\alpha$, PPAR $\beta / \delta$, and PPARY, are master metabolic regulators in response to dietary changes. PPAR $\alpha$ plays an important role in the regulation of fatty acid (FA) Catabolism (Staels et al, 1998). LXRs isoforms (LXR $\alpha$ and LXR $\beta$ ) are involved in lipogenesis and reverse cholesterol transport (Bensinger \& Tontonoz, 2008). Furthermore, PPARs and LXRs have also anti-inflammatory effects because they repress transcription of genes encoding pro-inflammatory cytokines (reviewed in Bensinger \& Tontonoz (2008)).

These nuclear receptors are abundantly expressed in metabolically active tissues, including the brain of rodents and humans (Warden et al, 2016). Because of their anti-inflammatory and potential neuroprotective effects, PPARs, LXRs, and RXRs activation with specific agonists emerged as promising approaches for treating brain pathologies in several mouse models of Parkinson, Huntington, Alzheimer diseases, multiple and amyotrophic lateral sclerosis, stroke, and even in a mouse model with physiological brain aging-dependent cognitive decline (reviewed in Moutinho \& Landreth (2017); Zolezzi et al (2017)).

Recent data indicate that activation of RXRs (Mariani et al, 2017) or PPARs (Roy et al, 2013) up-regulates the expression of a set of synaptic-related proteins involved in excitatory neurotransmission. Moreover, RXR activation increases dendritic complexity and branching of neurons promoting their differentiation and development (Mounier et al, 2015; Nam et al, 2016). However, the link between NRs activation and the improvement of synaptic plasticity is missing.

In the present work, we analyzed how RXR activation improves synaptic plasticity and neuronal function and identified PPAR $\alpha$ as a crucial player. Upon RXR activation, the PPAR $\alpha$-dependent

\footnotetext{
${ }^{1}$ Université Catholique de Louvain, Brussels, Belgium ${ }^{2}$ Institute of Neuroscience, Brussels, Belgium ${ }^{3}$ Laboratory of Neuroscience, Health Institute, University of Mons, Mons, Belgium ${ }^{4}$ Biomedical Research Institute, Hasselt University, Hasselt, Belgium ${ }^{5}$ de Duve Institute, Brussels, Belgium ${ }^{6}$ Université de Lille EGID, Inserm, CHU Lille, Institut Pasteur de Lille, Lille, France ${ }^{7}$ Laboratory of Histology and Neuropathology, Université Libre de Bruxelles, Brussels, Belgium
} 
up-regulation of GluA1 subunit-containing AMPA receptors mediates long-term potentiation (LTP) improvement in transgenic mice and AMPA responses in cortical cells. Associated with a higher expression of PPAR $\alpha$ in males than in females, the absence of PPAR $\alpha$ severely impairs LTP and GluA1 expression only in males. Knockdown of PPAR $\alpha$ in the hippocampus of cognition-impaired mice abrogates the beneficial effects of RXR activation only in males. In these mice, treatment with pemafibrate, a highly potent selective PPARa activator (Yamazaki et al, 2007; Hennuyer et al, 2016), improves synaptic plasticity only in males, demonstrating a key role of PPAR $\alpha$ in the regulation of synaptic function in a sexspecific manner.

\section{Results}

\section{Synaptic plasticity, AMPA responses, and GluA1 expression are improved upon RXR activation}

We first assessed in vivo the effect of RXR activation on synaptic plasticity in a well-characterized transgenic (Tg) mouse model of Alzheimer's disease (AD) (5xFAD), in which age-dependent synaptic and cognitive deficits occur (Oakley et al, 2006). We measured LTP in the hippocampal CA3-CA1 synapses, which are defined as an activity-dependent enhancement of synaptic strength involved in memory processing (Bliss \& Collingridge, 1993). Impaired LTP found in Tg 5XFAD hippocampus was recovered $(P<0.0001)$ after oral administration of bexarotene for $12 \mathrm{~d}$ and became similar to vehicle-treated control mice (Fig 1A). Bexarotene did not improve LTP of Wt mice (Fig S1A). The efficiency of the treatment of Tg mice could result from a breakdown of the blood-brain barrier in 5XFAD mice (Montagne et al, 2017). This recovery of LTP in 5XFAD mice was observed together with improved cognition in the object recognition and spatial navigation tasks, which was independent of amyloid plaque load in different regions of the brain (Fig S1B-E).

We next analyzed whether the RXR activation-mediated improvement of LTP was related to changes in expression levels of $\mathrm{N}$-methyl-D-aspartate receptors (NMDARs) and AMPA receptors (AMPARs), known to be required for LTP at the excitatory synapses (Bliss \& Collingridge, 1993). We, therefore, measured the expression of both GluN2A-, GluN2B-containing NMDARs, and GluA1-containing AMPARs in hippocampal lysates of these mice. Whereas GluN2A ( $P=$ $0.0070), 2 \mathrm{~B}(P=0.0019)$, and GluA1 $(P=0.0007)$ decreased in $\mathrm{Tg}$ mice compared with Wt mice, a 12-d treatment of Tg mice with the RXR agonist bexarotene specifically increased GluA1-containing AMPARs ( $P=0.0379)$ (Fig 1B). These results indicate that improvement in synaptic plasticity by RXR activation is tightly associated with an increased expression of GluA1 subunit in treated Tg animals.

The RXR activation-mediated GluA1 increase described above could have an impact on basal glutamatergic responses. Rat cortical cells in culture were treated or not with bexarotene (100 nM) for $24 \mathrm{~h}$, and NMDARs and AMPARs subunits measured. At 13-14 d in vitro (DIV), GluN2A $(P=0.0655)$ and 2B $(P=0.2916)$ were unchanged by bexarotene treatment (Fig $1 C$ ). In contrast, GluA1 protein was increased ( $P=0.0003)$ in these cells treated with bexarotene (Fig 1C). Increase in GluA1 protein level was also observed in hippocampal neurons $(P=0.0133)$ and in 7 DIV $(P=0.0273)$-cultured hippocampal slices incubated with a higher bexarotene concentration of $300 \mathrm{nM}$ (Figs S2A and 2B).

Because activation of AMPA and NMDA receptors mediates $\mathrm{Ca}^{2+}$ entry into cells, we monitored AMPA and NMDA-induced $\mathrm{Ca}^{2+}$ responses in cortical cell cultures with the Fura-2 $\mathrm{AM} \mathrm{Ca}^{2+}$-sensitive dye by using single-cell calcium imaging. Measurements of fluorescence intensity changes showed that only AMPA $(P<0.0001)$ (but not NMDA, $P>0.9999$ ) elicited a stronger $\mathrm{Ca}^{2+}$ increase with a larger amplitude in bexarotene-treated than in control cortical cells (Fig 1D). The higher $\mathrm{Ca}^{2+}$ permeability of GluA1-containing AMPARs observed in bexarotene-treated cortical cells did not result from changes in GluA2 expression, a subunit known to modify AMPARs properties by forming heteromeric complexes with GluA1 (reviewed in Derkach et al (2007)) (Fig S2C).

To address whether RXR activation induces membrane insertion of GluA1-containing AMPARs, we quantified GluA1 expressed at the cell surface following biotinylation of cell surface proteins in cortical cells treated or not with bexarotene. Activation of RXR increased GluA1 protein levels in both the total $(P=0.0002)$ and biotinylated $(P=0.0273)$ fraction as compared with control (Fig 1E). We next tested the influence of bexarotene treatment on the synaptic localization of GluA1-containing AMPARs, by measuring their co-localization with SynGAP, a Ras-GTPase-activating protein highly enriched at excitatory synapses (Chen et al, 1998). GluA1 fluorescence intensity was higher and exhibited a more punctuated pattern in bexarotene-treated cells compared with control (Fig $1 \mathrm{~F}$ and G). When postsynaptic puncta were quantified, GluA1containing AMPARs were increased by bexarotene compared with control (Fig $1 \mathrm{H}$ ) and exhibited a stronger overlap with the SynGAP postsynaptic marker after bexarotene treatment (Fig 1H). Concomitantly, a decrease in the number of SynGAP peaks by bexarotene was observed compared with control (Fig $1 \mathrm{H}$ ). In addition, a significant twofold increase in the average cluster size of GluA1 puncta $(P<0.0001)$ was observed when comparing treated with control cells (Fig 1I). Together, these results support the hypothesis that RXR activation improves AMPA responses by increasing GluA1 expression and its targeting to the excitatory synapses.

\section{PPAR $\alpha$ is necessary for RXR activation-mediated improvements}

Next, we investigated the cellular mechanisms by which RXR activation increases the expression of the GluA1-containing AMPARs. We first analyzed whether the expression of the CAMP response element binding (CREB) protein, involved in the synaptic maintenance of GluA1 subunit (Middei et al, 2013), was responsive to RXR activation (Nam et al, 2016). Both GluA1 $(P=0.0486)$ and CREB mRNA $(P=0.0007)$ as well as CREB protein $(P=0.0006)$ levels and immunostaining intensity were increased in bexarotene-treated cortical cells compared with control (Figs S3A and 3B).

Because RXR forms dimeric complexes with other NRs and that autoregulation and cross-regulation of NRs have been described (Tata, 1994; Lefebvre et al, 2010), we wondered whether the bexarotene-mediated RXR activation could modulate expression 
A

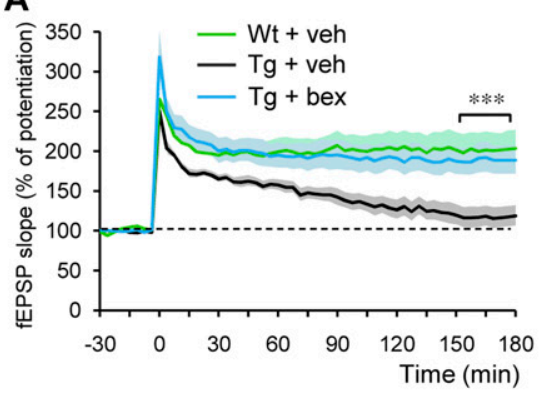

B Hippocampus

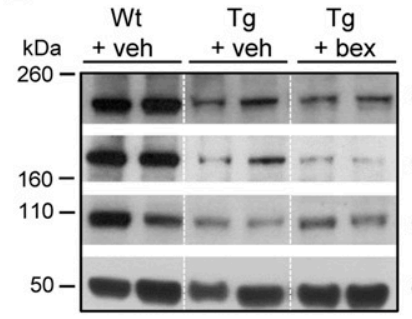

GluN2A GluN2B GluA1 a tubulin

\section{$\square$ GluN2A $\square$ GluN2B $\square$ GluA1}
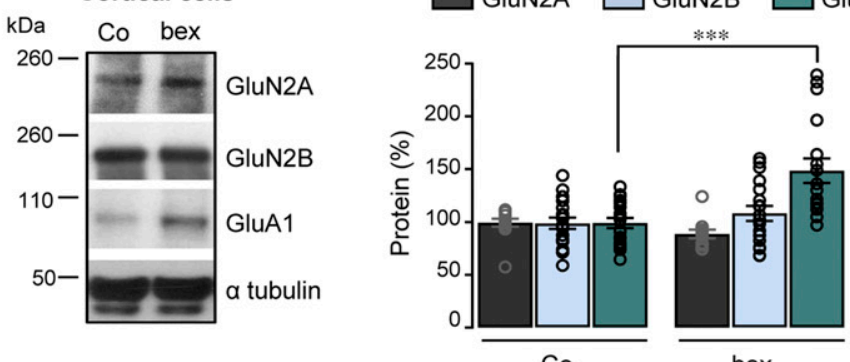

bex
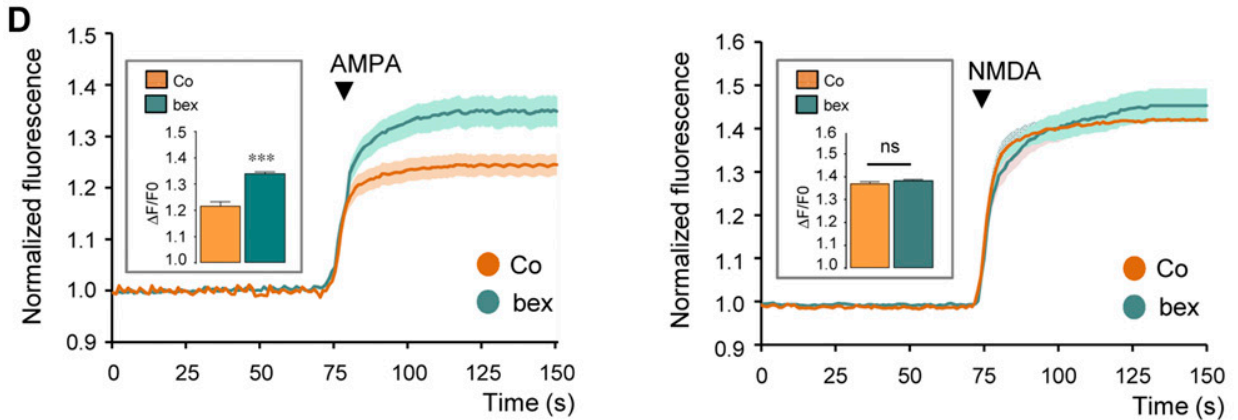

$\mathbf{E}$

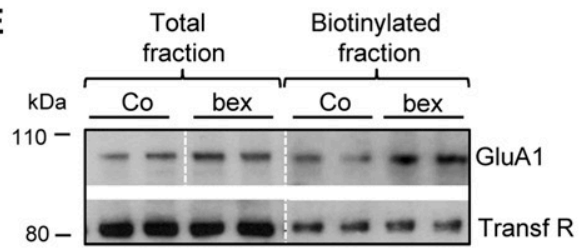

$\mathbf{F}$

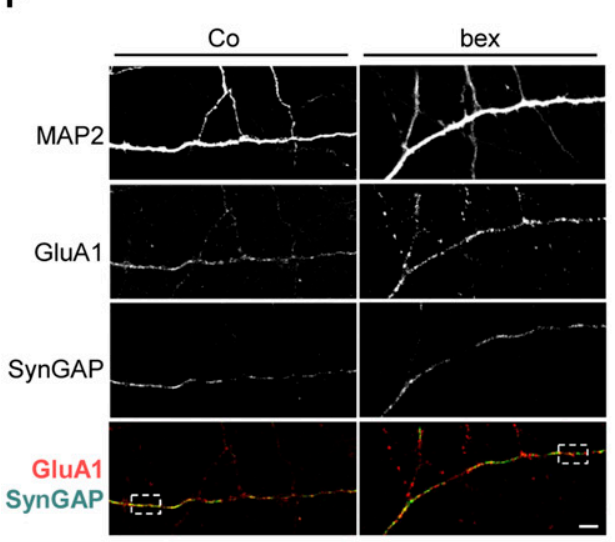

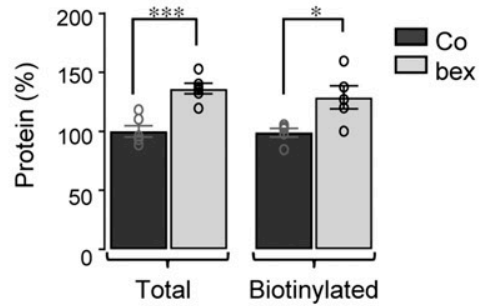

G
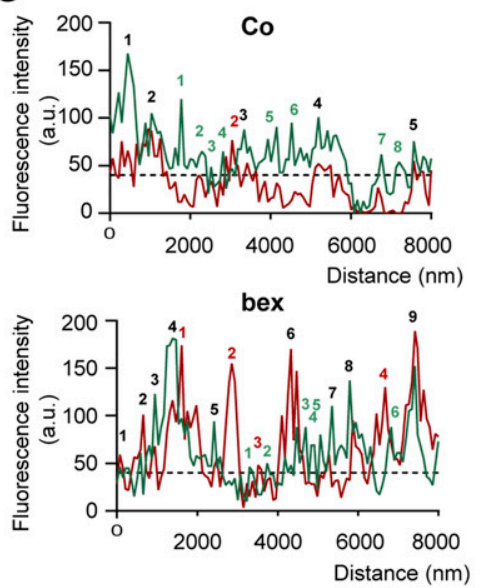

GluN2A $\square$ Glun2B $\square$ GluA1

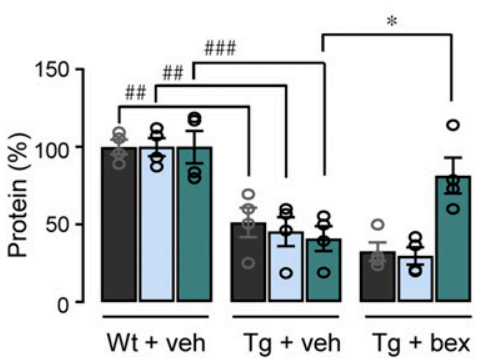


levels of the most prominent NRs found as obligate permissive heterodimers with RXR in neuronal and non-neuronal cells (reviewed in Bookout et al (2006); Zolezzi et al (2017)). We did not observe any modification in mRNA levels of RXR $\alpha(P>0.9999), \beta$ $(P=0.8478), y(P>0.9999), \operatorname{PPAR} \beta(P=0.2070), \operatorname{PPAR} y(P=0.3110)$, and $\operatorname{LXR} \beta(P=0.6481)$ isoforms in cortical cells treated with bexarotene (Fig 2A). In contrast, we observed a twofold increase in PPAR $\alpha(P=0.0005)$ mRNA levels (Fig 2A) together with an increased immunostaining of PPAR $\alpha$ in bexarotene-treated cortical cells compared with control (Fig S3C). These results indicate that bexarotene-mediated RXR activation specifically increases PPAR $\alpha$ expression.

We next analyzed whether up-regulation of GluA1 expression by RXR activation depends on PPAR $\alpha$ expression. We first measured GluA1 expression in cultured cortical cells from wild-type (Wt) and PPARa-deficient (Ppara ${ }^{-/-}$) mice (Figs S4A and 4B). As expected (Roy et al, 2013), absence of PPAR $\alpha$ decreased GluA1 expression at mRNA $(P=0.0079)$ and protein $(P<0.0001)$ levels in cortical cells (Figs S4C and 4D). In addition, the lower GluA1 expression in $\mathrm{Ppara}^{-/-}$cells was consistent with a decreased AMPA-induced $\mathrm{Ca}^{2+}$ response $(P<0.0001)$ in these cells (Fig S4E). A PPAR-responsive element was recently identified in the Creb promoter, identifying it as a PPAR $\alpha$ target (Roy et al, 2013), and we show that CREB mRNA $(P=0.0079)$ levels are decreased in Ppara $^{-/-}$ cells (Fig S4C).

To address whether the RXR activation-mediated GluA1 upregulation could be PPAR $\alpha$ dependent, Wt and Ppara ${ }^{-/-}$cultured cortical cells were treated or not with bexarotene. PPAR $\alpha$ deficiency totally prevented the increase in GluA1 mRNA and protein levels ( $P=$ 0.6385 and $P=0.1801$ ) observed in Wt cells treated with bexarotene (Fig 2B-D). On the contrary, the expression of ATP-binding cassette transporter A1 (ABCA1), a membrane protein driving cholesterol efflux (Venkateswaran et al, 2000), known to be regulated by LXR upon RXR activation, was still increased by bexarotene in Ppara ${ }^{-/-}$ cortical cells $(P<0.0001$, Fig $2 \mathrm{~B}$ and $P=0.0023$, Fig 2D). This clearly demonstrates that GluA1 but not ABCA1 expression is regulated by the RXR/PPAR $\alpha$ heterodimer.

Measurements of fluorescence intensity changes showed that AMPA elicited a greater $\mathrm{Ca}^{2+}$ increase with a larger amplitude only in Wt $(P<0.0001)$ but not in $P_{\text {para }}{ }^{-/-}(P>0.9999)$ cells treated with bexarotene (Fig 2E and F). Thus, increased expression of the GluA1 subunit of AMPARs by activation of RXR is PPAR $\alpha$ dependent.
PPAR $\alpha$ deficiency impairs LTP and GluA1 expression in male mice

PPAR $\alpha$ is required for normal cognitive function (D'Agostino et al, 2015; Roy et al, 2013). As previously reported (Dotson et al, 2016), PPAR $\alpha$ mRNA levels $(P<0.0001)$ are higher in the hippocampus of male than female mice (Fig $3 A$ ) prompting us to study potential sex different responses. Surprisingly, LTP induced by a single tetanus was significantly larger $(P<0.0001)$ in $5-6$-mo-old males than in females (Fig 3B). Interestingly, GluA1 mRNA $(P=0.0021)$ and protein $(P=0.0058)$ expression levels were higher in Wt male than female mice (Fig $3 C$ and D), although similar GluN2A and 2B mRNA and protein levels were measured in males and females (Fig $3 C$ and $D$ ).

Absence of PPAR $\alpha$ expression in 5-6-mo-old Ppara ${ }^{-1-}$ female mice did not influence either the potentiation induced by one train of stimulation or its maintenance as compared with Wt mice (Fig 3B and $E$ ). In contrast, both induction and maintenance of LTP were strongly reduced in Ppara $^{-/-}$male mice compared with Wt mice (Fig $3 B$ and $E$ ). A specific decreased expression of GluA1 was measured at the mRNA $(P=0.0012)$ and protein $(P=0.0003)$ level in Ppara $^{-/-}$ male mice but not in females (Fig $3 F$ and $G$ ). Taken together, these results suggest that PPAR $\alpha$ induces sex-dependent modifications in LTP by specifically affecting the expression of the GluA1 subunit of AMPARs only in male mice.

\section{Synaptic plasticity improved by RXR activation is PPAR $\alpha$ and sex dependent}

We next wondered whether the improved synaptic plasticity and GluA1 expression observed in bexarotene-treated Tg animals (5XFAD mice) are mediated by PPAR $\alpha$. Because disruption of PPAR $\alpha$ decreases lifespan in 5xFAD mice (Corbett et al, 2015), we decided to acutely decrease PPAR $\alpha$ expression in the hippocampus of 9-10mo-old Tg mice by using a serotype 9 adeno-associated viruses (AAVs) coding an shRNA construct designed to target endogenous PPAR $\alpha$ (AAV-ShPpara). A scrambled ShRNA (AAV-ShSc) was used as control. We first tested the efficiency of AAV-ShPpara construct in vitro following transduction of cultured cortical cells at 4 DIV. $10 \mathrm{~d}$ after transduction, PPAR $\alpha$ immunoreactivity was significantly decreased $(P=0.0152)$ in AAV-ShPpara compared with AAV-ShSctransduced cells (Fig S5A). Neuronal activity measured by spontaneous calcium oscillations and amplitude of AMPA-induced $\mathrm{Ca}^{2+}$ responses were reduced $(P<0.0001)$ in AAV-ShPpara compared

Figure 1. RXR activation ameliorates LTP, AMPA-induced responses, and GluA1 expression.

(A, B) Transgenic (Tg) 5xFAD and wild-type (Wt) mice treated at 9-10 mo with bexarotene (bex) (100 mg/ kg/d) or vehicle (veh) by gavage (12 d). (A) CA1 LTP in hippocampal slices of $\mathrm{Tg}+\operatorname{veh}(n=8)$ and $\mathrm{Tg}+\operatorname{bex}(n=7)$ compared with Wt + veh $(n=6) .{ }^{* * *} P<0.001, t$ test. (B) Representative Western blot of hippocampal lysates from Wt and Tg mice. Right panel: GluN2A, GluN2B, and GluA1/ $\alpha$ tubulin ratios. Results are expressed as percentage of Wt + veh ( $n=5$ for each); compared with Wt + veh: $\# \# P<0.01$, \#\#\#P<0.001 compared with Tg + veh: ${ }^{*} P<0.05$, ANOVA followed by Bonferroni's multiple-comparison posttest). (C) Representative Western blot of control (Co) and $100 \mathrm{nM}$ bex-treated $(24 \mathrm{~h}$ ) cell lysates from cortical cultures. Right panel: GluN2A, 2B, and GluA1/ $\alpha$ tubulin ratios. Results are expressed as percentage of respective Co (Co; $n=18$ and bex; $n=17$ of each analyzed in 10 independent experiments, ${ }^{* *} P<0.001$, Mann-Whitney test). (D) Normalized fluorescence intensity of Fura- 2 AM in Co and bex-treated cortical cells in the presence of AMPA (right panel) and NMDA (left panel). Insets: amplitude of AMPA (Co; $n=257$ and bex; $n=148$ cells analyzed in six and five independent experiments) and NMDA responses (Co; $n=307$ and bex; $n=177$ in seven and six independent experiments); ${ }^{* * *} P<0.001, n s$ : not significant ( $\left.P>0.05\right)$ Mann-Whitney test). (E) Cell surface biotinylation analyzed by Western blot (left panel). Right panel: GluA1/transferrin receptor (Transf R) ratios. Results are expressed as percentage of respective Co ( $n=6$ of each in three independent experiments, ${ }^{*} P<0.05,{ }^{* * *} P<0.001, t$ test). (F) Co and bex-treated MAP2-positive neurons immunolabelled for GluA1 (red) and SynGAP (green). Scale bar: $5 \mu \mathrm{m}$. (F, G, H) Representative profiles of the regions highlighted by the rectangles in merge pictures in (F). In $(\mathrm{H})$, the number of GluA1 (red numbers), SynGAP (green numbers), and GluA1/SynGAP overlapping (black numbers) peaks were quantified on >60 profiles per condition from four independent experiments. Results are expressed as percentage of total peaks from all the profiles. (I) Quantification of synaptic GluA1 puncta-cluster size (in $\mu \mathrm{m}^{2}$ ) in Co or bex-treated neurons. Results of $>900$ (from 23 images) and 1700 clusters (from 33 images) for Co and bex-treated neurons, respectively. ${ }^{* \star *} P<0.001$, $t$ test. Data information: data are presented as mean \pm SEM.

Source data are available for this figure. 

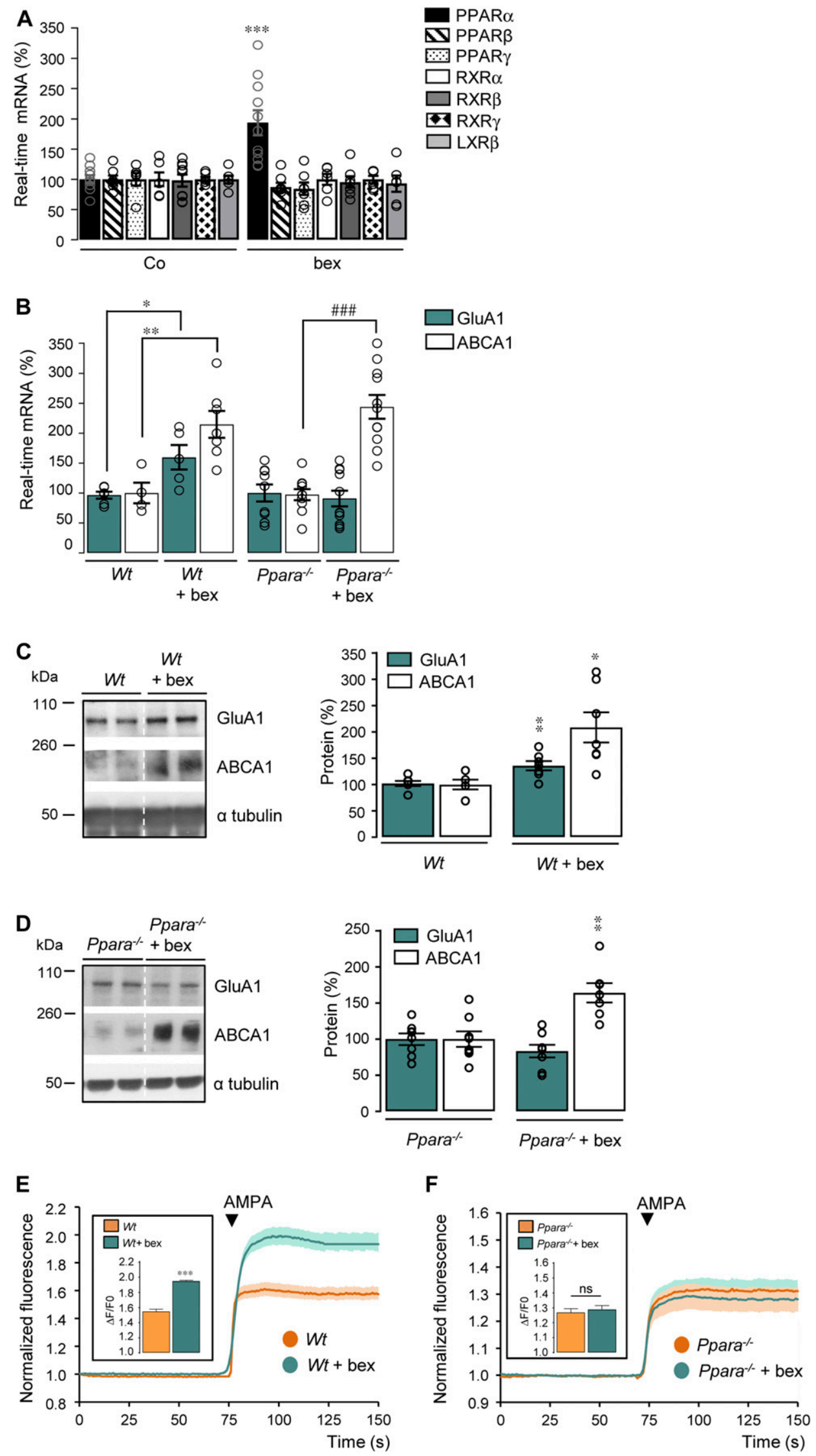

Figure 2. Absence of PPAR $\alpha$ abrogates GluA1 expression and AMPA responses induced by RXR activation.

(A) RT-qPCR analyses of Ppara, Pparb, Pparg, Rxra, Rxrg, and Nr1h2 mRNA levels in control (Co) and bexarotene (bex, $100 \mathrm{nM} / 24 \mathrm{~h}$ )-treated cortical cultures $(n=6-10$ in $3-5$ independent experiments), ${ }^{* * *} P<0.001, t$ test. (B) RT-qPCR analyses of Gria1 and Abca1 mRNA levels in three independent experiments from cortical cells prepared from wild-type ( $W t ; n=6$ of each) and Ppara-deficient Ppara $^{-/-} ; n=10$ of each) mice treated or not with bex. Results are expressed as percentage of corresponding non-treated cells (compared with Wt: ${ }^{\star} P<0.05,{ }^{\star *} P<0.01$; compared with Ppara ${ }^{-1-}$ : \#\#\#P<0.001 [t test]). (C, D) Representative Western blots of cortical cell lysates from Wt (C) and Ppara ${ }^{-/-}$(D) cultures treated or not with bex. Right panels: GluA1 and ABCA1/ $\alpha$ tubulin ratios. Results are expressed as percentage of respective untreated Wt or Ppara $^{-/-}\left(W t ; n=6, W t+\right.$ bex; $n=7$, Ppara $^{-/-} ; n=8$, and $\mathrm{Ppara}^{-1-}+$ bex; $\mathrm{n}=7$ of each analyzed in three independent experiments; ${ }^{*} P<0.05,{ }^{* *} P<$ $0.01, t$ test, except for ABCA1 in $W t+$ bex: Mann-Whitney test). (E, F) AMPA-induced calcium fluorescence in Wt (E) and Ppara -/- (F) cortical cells treated with bex. Insets: AMPA responses amplitude $(W t ; n=320, W t+$ bex; $n=$ 118, Ppara $^{-/-} ; n=430$, and Ppara ${ }^{-/-}+$bex; $n=374$ cells analyzed in three to six independent experiments; ${ }^{* * *} P<0.001$, ns: not significant $[P>$ 0.05], Mann-Whitney test). Data information: data are presented as mean \pm SEM.

Source data are available for this figure. 

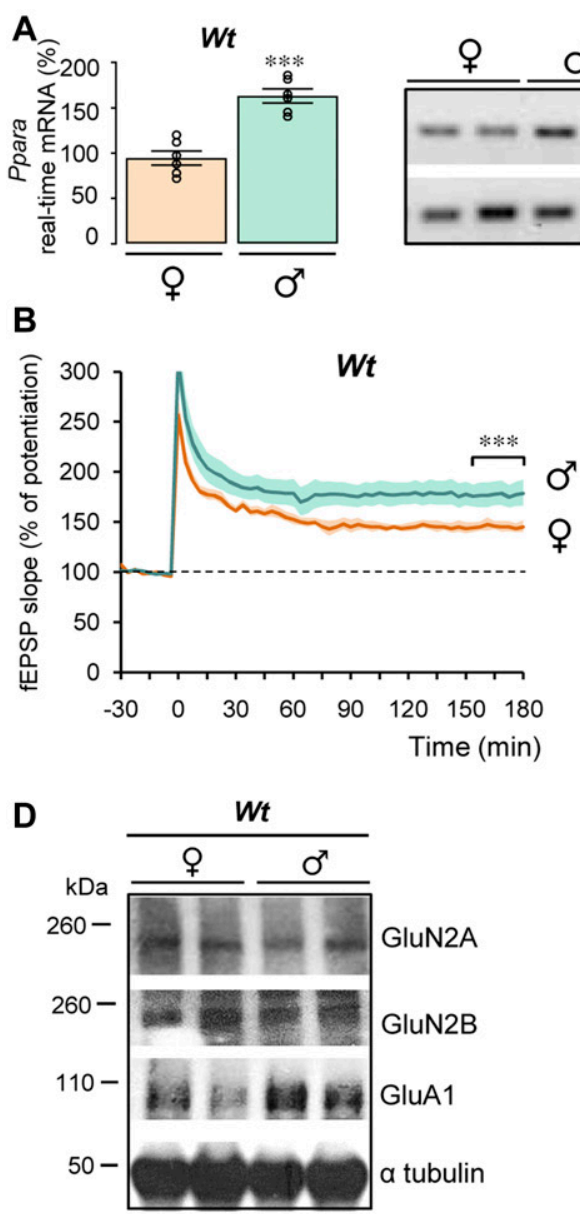

E

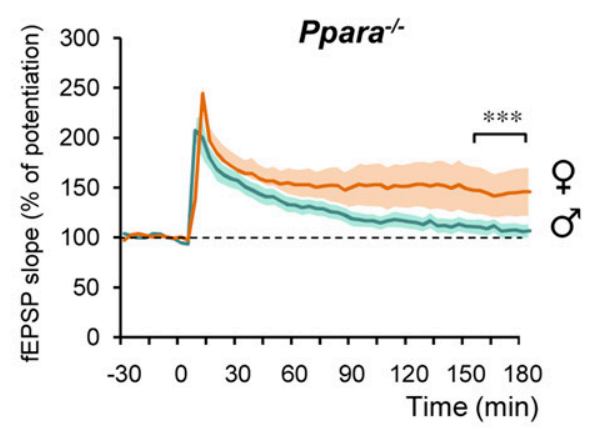

G

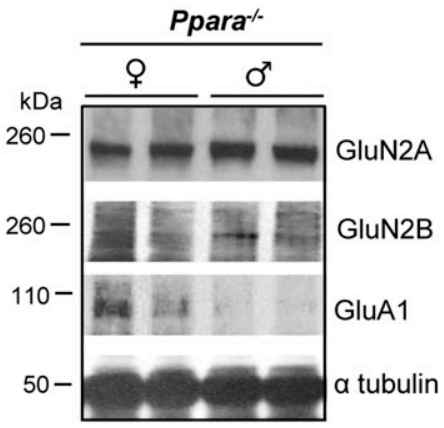

C

GluN2A $\square$ GluN2B $\square$ GluA1

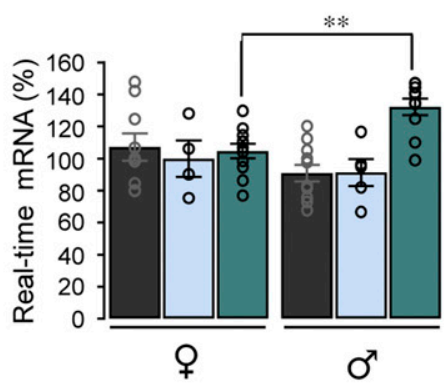

GluN2A $\square$ GluN2B $\square$ GluA1

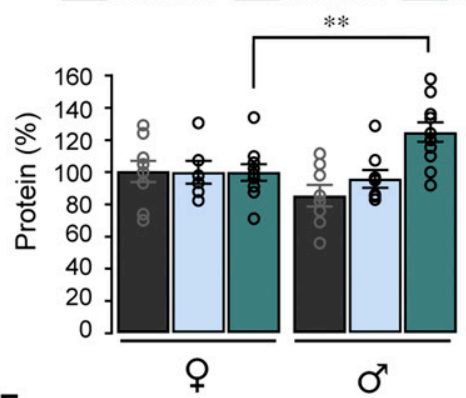

$\mathbf{F}$

GluN2A $\square$ GluN2B $\square$ GluA1

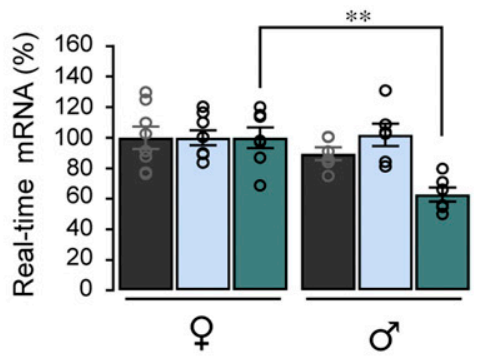

GluN2A $\square$ GluN2B $\square$ GluA1

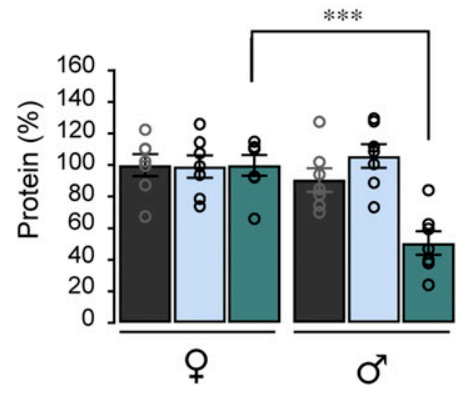

Figure 3. PPAR $\alpha$ deficiency impairs LTP and GluA1 expression in male mice.

(A) PPAR $\alpha$ mRNA levels analyzed in the hippocampus from female ( $\left(\right.$ ) and male ( $\left.{ }^{\star}\right)$ wild-type (Wt) mice by RTqPCR and semi-quantitative RT-PCR (left and right panels, respectively). Results are expressed as percentage of corresponding $q$ ( $n=6$ of each, ${ }^{* * *} P<$ $0.001, t$ test). (B, E) CA1 LTP in hippocampal slices from 5-6-mo-old male ( $\left.\delta^{*}\right)$ and female (\$) wild-type (Wt, in

(B)) and Ppara-deficient (Ppara ${ }^{-/-}$, in (E)) mice ( $n=6$ in each group). ${ }^{* * *} P<0.001, t$ test. (C, F) RT-qPCR analyses of Grin2A and $2 B$ and Gria1 mRNA levels in the

hippocampus from female ( $\%)$ and male $(\delta)$ Wt $(n=11)$ and Ppara $^{-1-}(n=6-8)$ mice. Results are expressed as percentage of corresponding $q$ (in (C) compared with Wt $q$ : ${ }^{* *} P<0.01$, Mann-Whitney test; in ( $F$ ) compared with Ppara $^{-/-}$$q:{ }^{* *} P<0.01, t$ test). (D, G) Representative Western blots of hippocampal lysates from female ( $($ ) and male ( $\left.\sigma^{*}\right)$ Wt and Ppara ${ }^{-/-}$mice. Right panels: quantification of GluN2A, GluN2B, and GluA1/ $\alpha$ tubulin ratios. Results are expressed as percentage of corresponding $q$ (in (D) compared with Wt $q$ : ${ }^{* *} P<0.01$, in (G) compared with Ppara ${ }^{-1-}$ o: ${ }^{* * *} P<0.001, t$ test) (Wt: $\mathrm{n}=8-10$ and Ppara $^{-/-} ; \mathrm{n}=7$ for each condition). Data information: data are presented as mean \pm SEM. Source data are available for this figure. 
A

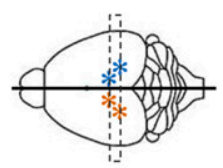

B $\square$ Tg AAV-ShSc* $\square$ Tg AAV-ShPpara*
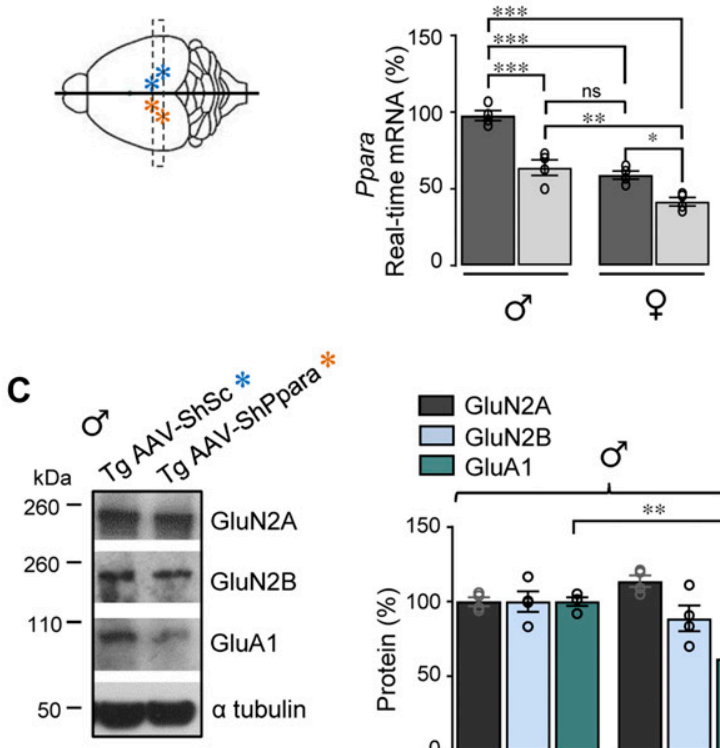

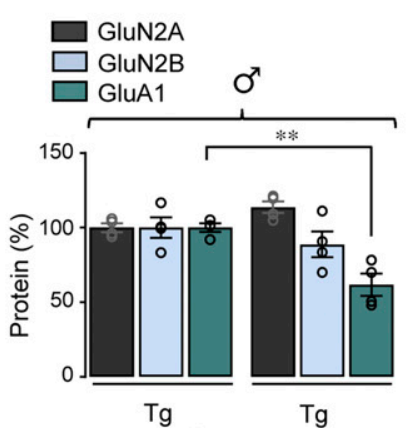

AAV-ShSc AAV-ShPpara

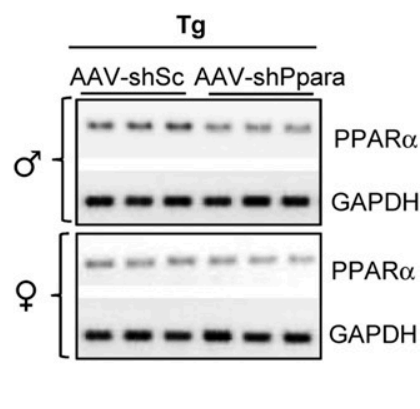

Figure 4. LTP improvement by RXR activation is PPAR $\alpha$ and sex dependent.

(A) Schematic drawing of the top view of a mouse brain. Stars: ipsi and contralateral injection sites of Ppara and scramble shRNA AAV (AAV-ShPpara [orange] and AAVShSc [blue]). (B-D) Dashed line represents the plane of the coronal section used in (B-D) for biochemical analyses. (B) RT-qPCR analyses of Ppara mRNA levels in male ( $\widehat{(})$ and female () Tg mice hippocampi AAV-ShSc and AAV-ShPpara injected at 9-10 mo. Results are expressed as percentage of AAV-ShSc-injected male mice ( $\mathrm{n}=4$ of each; ${ }^{*} P<0.05,{ }^{* *} P<0.01,{ }^{* * *} P<0.001$, ns: not significant $(P>0.05)$, ANOVA followed by Bonferroni's multiple-comparison posttest). Right panels: PPAR $\alpha$ semi-quantitative RT-PCR. (C, D) Representative Western blots of hippocampal lysates from male ( $\$$, in C) and female ( $q$, in D) Tg mice AAV-ShSc and AAV-ShPpara injected. Right panels: quantification of GluN2A, GluN2B, and GluA1/ $\alpha$ tubulin ratios in male (in C) and female (in D) Tg mice AAV-ShSC and AAVShPpara injected. Results are expressed as percentage of corresponding Tg mice AAV-ShSc injected ( $n=4$ in each condition, ${ }^{* *} P<0.01$, $t$ test; ns: not significant $[P>$ 0.05]). (E, F) CA1 LTP in hippocampal slices from male ( $\$$, in (E)) and female (o, in (F)) transgenic (Tg) 5xFAD mice (9-10 mo) AAV-ShPpara and AAV-ShSc injected and perfused with $4 \mu \mathrm{M}$ bexarotene (bex) ( $n=4$ in each group, ${ }^{\star \star *} P<0.001, t$ test). Data information: data are presented as mean \pm SEM

Source data are available for this figure.

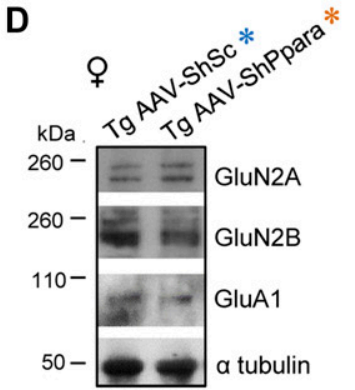

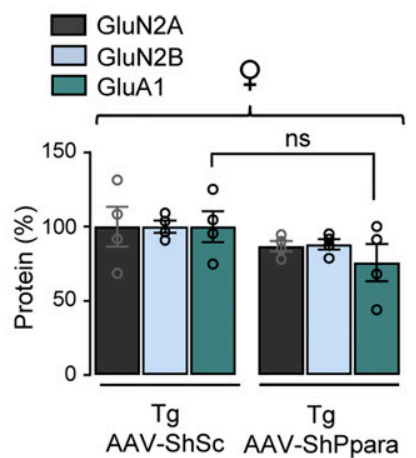

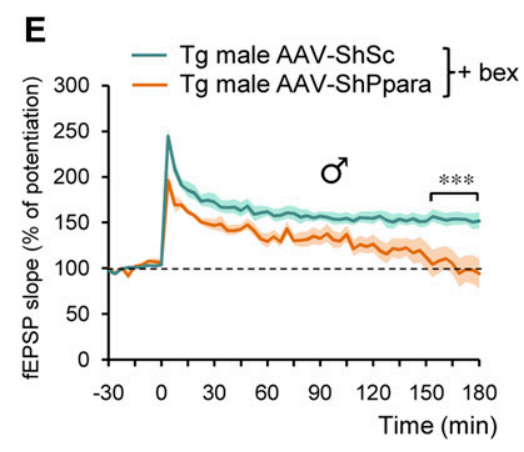

$\mathbf{F}$

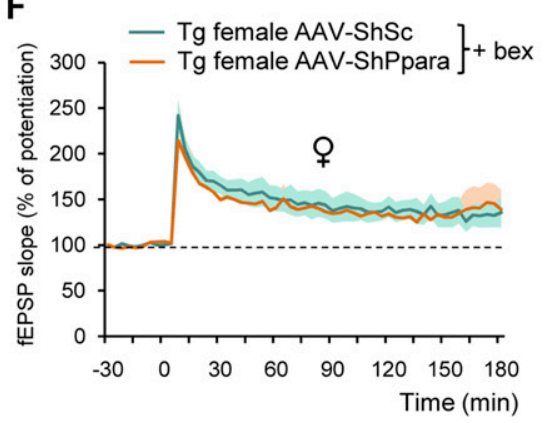

with AAV-ShSc infected cells (Figs S5B and 5C, respectively). PPAR $\alpha$ knockdown, although not affecting ABCA1 expression ( $P>0.9999)$, decreased GluA1 mRNA $(P=0.0005)$ and protein $(P<0.0001)$ levels by about 50\% (Fig S5D). In addition, PPAR $\alpha$ knockdown abolished the increase in GluA1 mRNA and protein levels $(P=0.6051$ and $P=$ 0.1655 , respectively) observed in AAV-ShSc cells treated with bexarotene (100 nM, 24 h) (Figs S6A and 6B). On the contrary, ABCA1
mRNA and protein expression were still induced in AAV-ShSC $(P=$ 0.0058 and $P<0.0001$, respectively) and AAV-ShPpara $(P=0.0052$ and $P<0.0001$, respectively) cortical cells treated with bexarotene (Figs S6A and 6B). Measurement of fluorescence intensity changes showed that AMPA elicited a greater $\mathrm{Ca}^{2+}$ increase $(P<0.0001)$ with a larger amplitude only in AAV-ShSc but not in AAV-ShPpara $(P>$ 0.9999)-transduced cells treated with bexarotene (Figs S6C and 6D). 
A
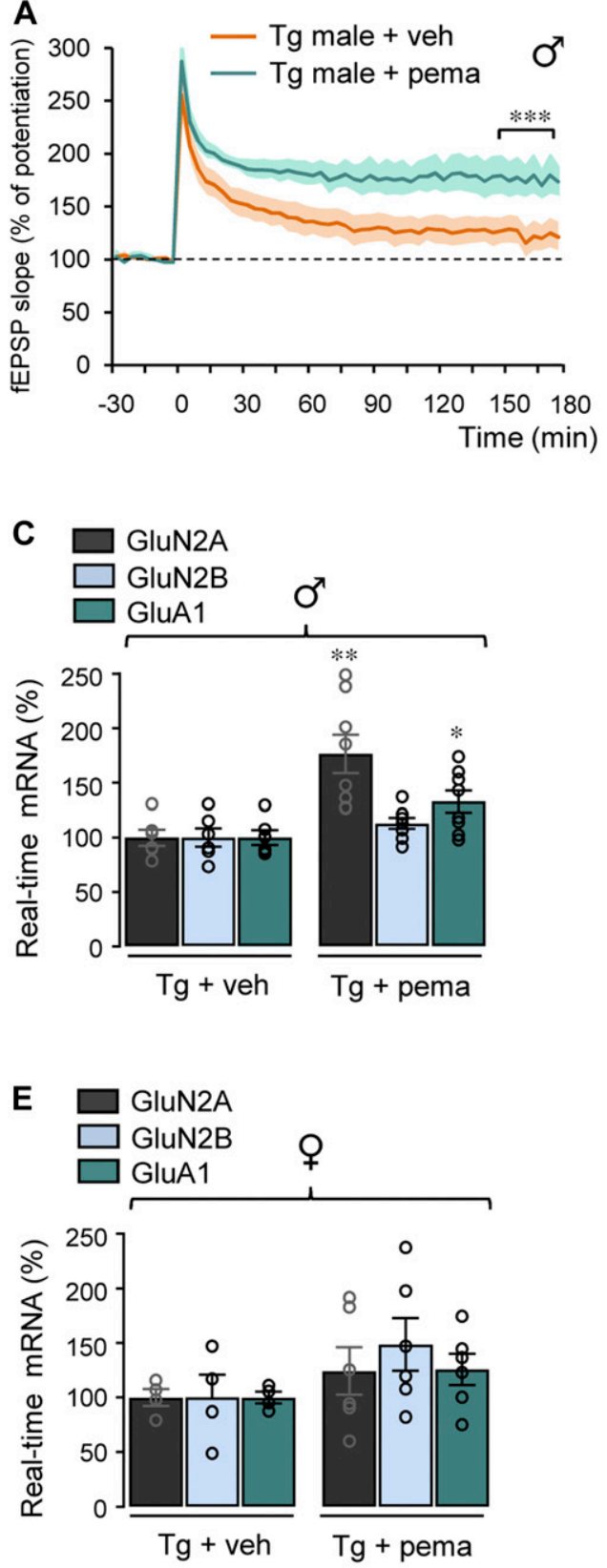

B

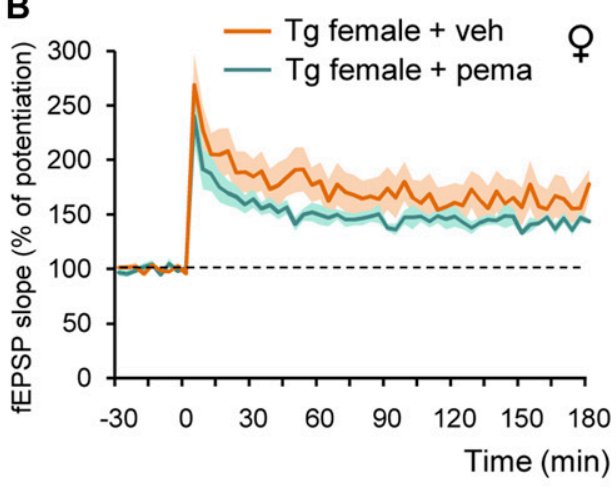

D
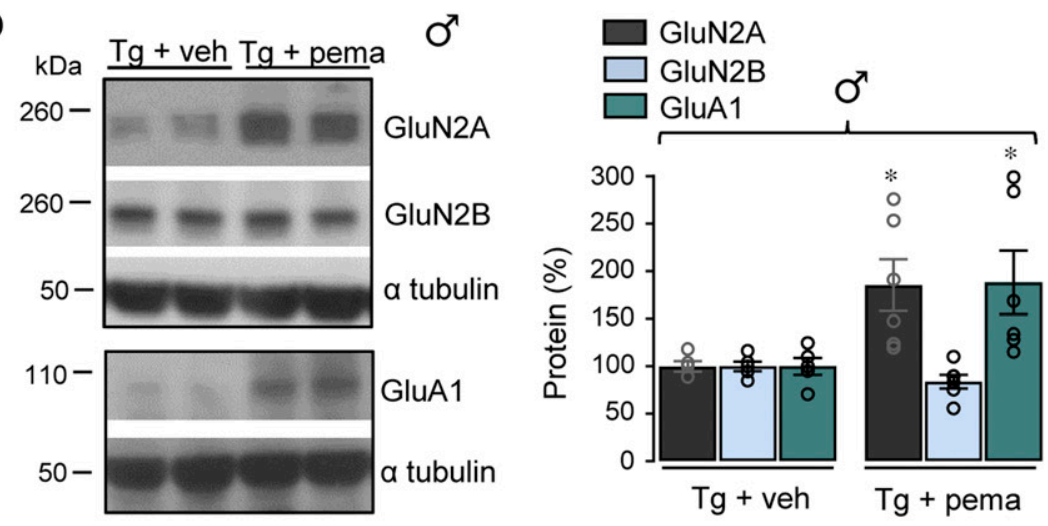

$\mathbf{F}$

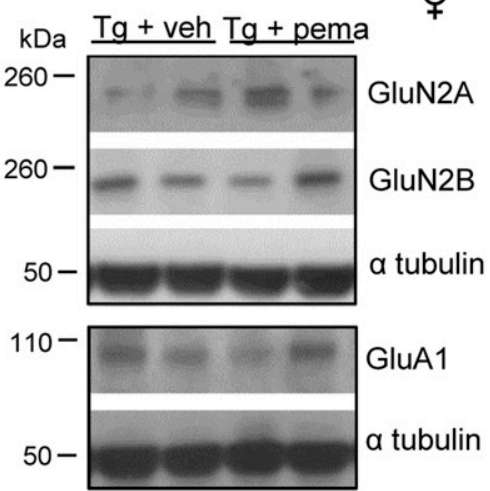

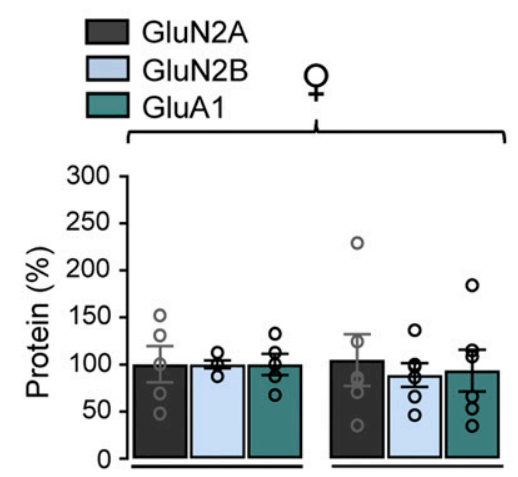

$\mathrm{Tg}+\mathrm{veh}$

$\mathrm{Tg}+$ pema

Figure 5. Sex-specific improvement of LTP by pemafibrate.

(A, B) Male ( $($ ) and female (\$) transgenic (Tg) 5xFAD mice treated at 12 mo with pemafibrate (pema) (1 mg/kg/d) or vehicle (veh) by gavage (12 d). CA1 LTP in hippocampal slices of male Tg + veh $(n=6)$ and Tg + pema mice $(n=8)$ in $(A)$ and female Tg + veh $(n=4)$ and Tg + pema mice $(n=6)$ in $(B)$, ${ }^{* * * P<0.001, t \text { test. }(C, E) R T-q P C R}$ analyses of Grin2A and 2B and Gria1 mRNA levels in the hippocampus from male Tg mice treated with pema $(n=8)$ or veh $(n=6$ for each condition) in (C) and from female Tg mice treated with pema $(n=6)$ or veh $\left(n=4\right.$ of each) in (E). Results are expressed as percentage of corresponding $\operatorname{Tg}+\operatorname{veh}\left({ }^{*} P<0.05,{ }^{* \star} P<0.01 ; t\right.$ test). (D, F) Representative Western blots of hippocampal lysates from male (D) and female (F) Tg mice treated or not with pema. Right panels: quantification of GluN2A, GluN2B, and GluA1/ $\alpha$ tubulin ratios. Results are expressed as percentage of corresponding $T g+v e h\left(T g+v e h n=5\right.$ and $T g+$ pema $n=6$ of each, ${ }^{*} P<0.05, t$ test). Data information: data are presented as mean \pm SEM.

Source data are available for this figure.

We next analyzed in vivo the effect of the acute knockdown of PPAR $\alpha$ expression after stereotaxic injection of AAV-ShPpara and AAV-ShSc constructs in the right and left hippocampi of Tg mice, respectively (Fig 4A). Because PPAR $\alpha$ and GluA1 expressions differ between males and females, the effect of knockdown of PPAR $\alpha$ was studied in males and females separately. PPAR $\alpha(P=0.0019)$ and GluA1 $(P=0.0103)$ mRNA as well as GluA1 $(P=0.0021)$ protein levels were higher in males compared with females (Figs S7A and 7B). 3 wk after stereotaxic AAV injection, PPAR $\alpha$ mRNA levels $(P=0.0001)$ significantly decreased in the hippocampi of male Tg mice injected 
A
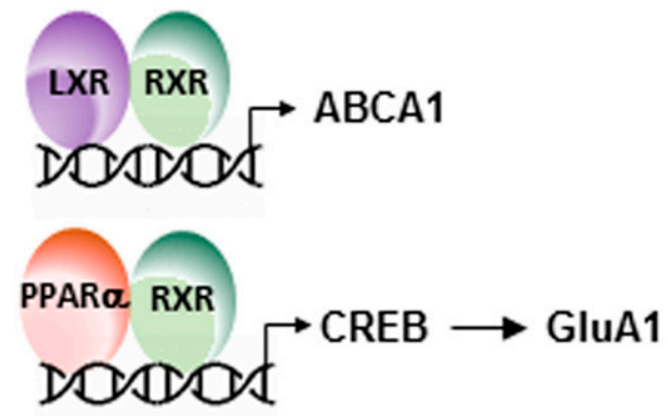

B

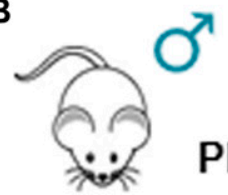

PPAR $\alpha>$ PPAR $\alpha$

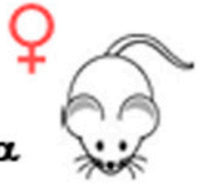

GluA1 > GluA1

\section{Synaptic plasticity $>$ Synaptic plasticity}

Figure 6. Sex- and PPAR $\alpha$-specific effects on GluA1 expression and synaptic plasticity.

(A) Schematic representation of LXR/RXR and PPAR $\alpha / R X R$ heterodimers bound to a specific DNA sequence. LXR/RXR drives the expression of ABCA1 and $P P A R \alpha / R X R$ drives the expression of CREB, which in turn, drives the expression of GluA1. (B) PPAR $\alpha$ and GluA1 expression are higher $(>)$ in male ( $\left.\delta^{*}\right)$ than in female (\$) mice. The gene dosage effect of PPAR $\alpha$ on GluA1 expression leads to a better $(>)$ synaptic plasticity in male than in female mice.

with AAV-ShPpara to levels similar $(P=0.7796)$ to those detected in female Tg mice injected with AAV-ShSc (Fig 4B). A significant, but less pronounced, decrease in PPAR $\alpha$ mRNA $(P=0.0239)$ was also observed in female Tg mice injected with AAV-ShPpara (Fig 4B), an effect likely due to the lower baseline PPAR $\alpha$ expression in female mice (Fig 4B). In association with this difference in PPARa expression between males and females, PPAR $\alpha$ knockdown decreased GluA1 protein levels $(P=0.0028)$ only in hippocampal lysates from male Tg mice injected with AAV-ShPpara but not in females $(P=0.1894)$ (Fig $4 C$ and $D)$. GluN2A and 2B protein expression was not affected by the treatment (Fig $4 C$ and D). Next, we wondered whether PPAR $\alpha$ was needed for the recovery of synaptic plasticity induced by RXR activation. We first measured LTP on hippocampal slices from male Tg mice treated or not for $2.5 \mathrm{~h}$ with bexarotene $4 \mu \mathrm{M}$ (Fig S7C). The results were similar to those obtained following gavage of Tg mice. LTP was then measured on hippocampal slices from male and female $\mathrm{Tg}$ mice injected with AAV-ShPpara or AAV-ShSc and incubated with bexarotene $4 \mu \mathrm{M}$. After $2.5 \mathrm{~h}$ of bexarotene incubation, the potentiation induced by high-frequency stimulation was lower in male Tg male mice injected with AAV-ShPpara compared with those injected with AAVShSc (Fig 4E). Moreover, LTP progressively decreased $(P<0.0001)$ in male Tg mice injected with AAV-ShPpara compared with male Tg mice injected with AAV-ShSc $3 \mathrm{~h}$ after the train of stimulation (Fig $4 \mathrm{E}$ ). Both induction and maintenance of LTP were not affected in female Tg mice injected with AAV-ShPpara compared with AAV-ShSC
(Fig 4F). Taken together, these results show that improvement of synaptic plasticity by RXR activation is PPAR $\alpha$ - and sex dependent.

\section{Sex-specific improvement of LTP by pemafibrate}

We then tested the effect of direct activation of PPAR $\alpha$ using pemafibrate, a selective agonist for PPAR $\alpha$ (Yamazaki et al, 2007; Hennuyer et al, 2016). We first assessed in vivo the effectiveness of PPAR $\alpha$ activation in 12-mo-old male and female Tg (5xFAD) mice treated for $12 \mathrm{~d}$ by oral gavage with pemafibrate (Hennuyer et al, 2016) or vehicle. As previously described in human hepatocytes and mouse liver (Raza-lqbal et al, 2015), we observed an increase in mRNA levels of PDK4 ( $P=0.0049)$, a PPAR $\alpha$ target gene, in hippocampal lysates from Tg mice treated with pemafibrate (Fig S8A). These results demonstrate that oral administration of pemafibrate is able to activate PPAR $\alpha$ in the brain.

We then measured the effect of pemafibrate on LTP. Although $\operatorname{PPAR} \alpha(P=0.0070), \operatorname{PPAR} \beta(P=0.0348)$, and PPARY $(P=0.0083) \mathrm{mRNA}$ levels were lower in Tg compared with Wt mice (Fig S8B), the decreased LTP observed in male Tg mice treated with vehicle was nevertheless recovered $(P<0.0001)$ following treatment with pemafibrate (Fig 5A). Both induction and maintenance of LTP were strongly improved in male Tg mice with pemafibrate compared with vehicle (Fig 5A). However, activation of PPAR $\alpha$ in female Tg mice did not influence LTP potentiation nor its maintenance compared with vehicle (Fig 5B). In male Tg mice treated with pemafibrate, mRNA and protein levels of the GluN2A $(P=0.0037$ and $P=0.0214$, respectively) and GluA1 $(P=0.0276$ and $P=0.0453$ ) subunits were significantly up-regulated compared with male Tg mice treated with vehicle (Fig 5 C and D, respectively). No significant increase in the NMDARs and AMPARs subunits was measured in pemafibrate compared with vehicle-treated female Tg mice (Fig 5E and F). Taken together, these results show that activation of PPAR $\alpha$ with pemafibrate improves synaptic plasticity in a sex-specific manner with a pharmacological response (increase in both GluN2A and GluA1 expression) different from that resulting from RXR activation (increase in GluA1 expression).

\section{Discussion}

We report here that PPAR $\alpha$, a master metabolic regulator involved in FA catabolism (Staels et al, 1998), plays a central role in hippocampal synaptic plasticity by driving the expression of the GluA1 subunit of AMPARs in a sex-specific manner.

We show that LTP improvement observed in a Tg mouse model of $A D$ upon RXR activation with bexarotene is concomitant with the specific up-regulation of GluA1 expression. Adult GluA1 knockout mice cannot generate LTP and have cognitive abnormalities (Schmitt et al, 2005), indicating that the GluA1 subunit plays a critical role in synaptic plasticity and cognition. Even in the absence of any modification in NMDARs subunits, we cannot rule out that changes in subunit composition or posttranslational modifications that affect NMDARs gating and trafficking and also AMPARs function (for review see Derkach et al (2007)), could occur following RXR activation. 
In cortical cells in culture, we show that RXR activation with bexarotene induces a cell-autonomous increase in the expression of the GluA1 subunit. We show that GluA1 up-regulation induced by RXR activation was totally abolished in the absence of PPAR $\alpha$, whereas the expression of the LXR target gene, ABCA1, was still induced. Therefore, RXR/LXR activation increases ABCA1 gene transcription, whereas RXR/PPAR $\alpha$ activation drives the up-regulation of GluA1 expression (Fig 6A).

Because of differences in expression levels of PPAR $\alpha$ between males and females (Dotson et al, 2016), a sex difference in the regulation of GluA1 expression and synaptic plasticity by PPAR $\alpha$ was found (Fig 6B). Many different pathways, which do not involve PPAR $\alpha$, can control GluA1 expression, and we cannot conclude that LTP difference between WT males and females relies only on a differential expression of PPAR $\alpha$. Nevertheless, a two times higher expression of PPAR $\alpha$ in males than in females induces a PPAR $\alpha$ mediated regulation of GluA1 expression only in males. This suggests that a threshold level of PPAR $\alpha$ expression is needed to regulate GluA1 expression, and this level is not reached in females, which are insensitive to bexarotene treatment. Hormones are known to influence the expression of PPAR $\alpha$ in a sex-specific manner because gonadectomy of male rats decreases PPAR $\alpha$ expression levels (Jalouli et al, 2003). Estrogens are known to improve synaptic plasticity, and behavior is affected in ovariectomized female rats (reviewed in Arevalo et al (2015)).

Consistent with the central role of PPAR $\alpha$ in FA catabolism (Staels et al, 1998), PPARa null mice exhibit greater lipid accumulation (Chung et al, 2018). PPAR $\alpha$ gene expression levels dosedependently control liver metabolism, inflammation, and atherogenesis (Lalloyer et al, 2011) and are tightly regulated by cellular content in FA. Low plasma-free FA increases PPAR $\alpha$ mRNA level in human skeletal muscle (Watt et al, 2004), whereas lipid accumulation decreases PPAR $\alpha$ expression in the renal tubular epithelial region in rats (Chung et al, 2018), suggesting that the availability of FA is important for the regulation of Ppara gene transcription. Accumulation of FA has been previously reported in female but not male mice carrying FAD mutations (Barrier et al, 2010). Such FA accumulation could explain why PPAR $\alpha$ expression is lower in female 5xFAD Tg mice.

Fibrates are PPAR $\alpha$ agonists used in the treatment of hypertriglyceridemia, mixed dyslipidemia, and also prevent the progression of atherosclerotic lesions (reviewed in Gross et al (2017)). Fenofibrate has been widely used, but its relatively low activity on PPAR $\alpha$ led to the development of pemafibrate, a more potent and selective agonist for PPARa (Yamazaki et al, 2007; Hennuyer et al, 2016). In recent clinical studies, pemafibrate improved lipid profiles in patients with type 2 diabetes and hypertriglyceridemia (Araki et al, 2018) with a much higher efficacy than fenofibrate (Ishibashi et al, 2018). We show here that pemafibrate significantly improved hippocampal LTP in male but not in female Tg mice, confirming the involvement of PPAR $\alpha$ in synaptic plasticity in a sex-specific manner.

Whereas hippocampal LTP was improved by both pemafibrate and bexarotene treatments of male Tg mice, pemafibrate administration increased expression of both GluN2A and GluA1 whereas bexarotene only increased expression of GluA1. Although PPAR/RXR heterodimers are permissive (Evans \& Mangelsdorf, 2014), it was previously demonstrated that the conformation of the ligandreceptor complexes and the nature of their interaction with coregulators can differently modulate the transcription of target genes (Dowell et al, 1997; Schulman et al, 1998; Perez et al, 2012). We, therefore, hypothesize that because of their different affinities for different cofactors, bexarotene could up-regulate only GluA1, whereas pemafibrate is able to drive the expression of both GluA1 and GluN2A subunits. Consequently, LTP improvement observed upon RXR and PPAR $\alpha$ activation relies mainly on GluA1, but we cannot exclude that GluN2A could also be involved when PPAR $\alpha$ is activated by pemafibrate. Although this study strongly supports that targeting PPAR $\alpha$ could be an effective strategy to improve synaptic plasticity deficits related to cognitive defects ( $D$ 'Orio et al, 2018), it presents some limitations. Our study was limited to the 5XFAD mouse model of AD. Therefore, further investigations are needed to confirm whether PPAR $\alpha$ could be an interesting target in other mouse models of neurodegenerative diseases including Alzheimer, Parkinson, and Huntington diseases, as well as multiple and amyotrophic lateral sclerosis, in which cognitive impairments occur. These mouse models do not fully recapitulate all pathological changes observed in patients and translating synaptic plasticity changes in mice with cognitive deficits in humans is challenging. However, based on the observations that bexarotene improves cognition in mouse models, we previously reported that Targretin (bexarotene) improved cognition in a patient with mild AD (Pierrot et al, 2016). In the same way, pemafibrate is used in human phase III clinical trials (Araki et al, 2018; Ishibashi et al, 2018), and investigating its effects on cognition in humans could be an interesting translational study based on our results.

Despite these limitations, we report here a sex-regulated gene dosage effect of PPAR $\alpha$ on synaptic plasticity. In animal models, sex differences should be considered rather than making the choice of the best responder. In humans, sex differences exist in the vulnerability, incidence, manifestation, and treatment of numerous neurological and psychiatric diseases (Riecher-Rossler, 2017). Our results outline the importance to decipher sex differences in neurodegenerative diseases, including AD (Ferretti et al, 2018) with complex cognitive and neuropsychiatric symptoms, to define new sex-specific therapeutic strategies.

\section{Materials and Methods}

\section{Animals}

All animal procedures used in the study were carried out in accordance with the institutional and European guidelines as certified by the local Animal Ethics Committee. Both pregnant Wistar rats used for embryonic cell cultures of either sex were obtained from Université catholique de Louvain (UCL, Brussels, Belgium) animal facilities. All protocols were approved by the local ethical committee of the UCL. 5xFAD (Oakley et al, 2006) mice were obtained from Jackson Laboratories (strain: B6SJL-Tg (APPSWFILon, PSEN1*M146L*L286V) 6799Vas/Mmjax), bred as heterozygous 5XFAD mice. 5-6-mo-old PPAR $\alpha$-deficient $\left(\mathrm{Ppara}^{-/-}\right.$) mice were used (Lee et al, 1995). Age-matched non-transgenic wild-type littermates were 
used as controls. Experiments performed with male and female separately were indicated. Animals were housed on a 12-h light/ dark cycle in standard animal care facilities.

\section{Reagents and antibodies}

When unmentioned, reagents for cell culture, Western blotting, and calcium imaging were purchased from Thermo Fisher Scientific. Antibodies were purchased as indicated. Primary antibodies: mouse monoclonal anti-Glutamate Receptor 2 (6C4), rabbit monoclonal anti-GluA1 (C3T), and anti-GluN2A antibodies (Cat. No. MAB397, 04-855, and 07-632, respectively; Merck Millipore); mouse monoclonal anti-GluN2B (Cat. No. 610417; BD Biosciences); goat polyclonal anti-SYNGAP (Cat. No. LS-C154908; Bio-Connect Life Sciences); mouse monoclonal anti-ABCA1 (Cat. No. ab18180; Abcam); mouse monoclonal anti- $\alpha$ tubulin and mouse monoclonal antiMAP2 (Cat. No. T6074 M4403 and A2066, respectively; Sigma-Aldrich); and anti-Transferrin Receptor mouse monoclonal antibody (H68.4) (Cat. No. 13-6800; Thermo Fisher Scientific). Secondary antibodies: donkey anti-rabbit and anti-mouse IgG horseradish (HRP) linked (Cat. No. NA934 and NA931, respectively; GE Healthcare-Life Sciences); Alexa Fluor 647 goat anti-mouse IgG1, 488 chicken anti-goat $\operatorname{lgG}(\mathrm{H}+\mathrm{L})$, and 568 goat anti-rabbit IgG $(\mathrm{H}+\mathrm{L})$ (Cat. No. A21240, A21467, and A11036, respectively; Thermo Fisher Scientific).

\section{Cell cultures}

Hippocampal and cortical neuronal cultures were prepared from embryonic day 17 (E17) to E18 Wistar rats or P0-P1 pups from Ppara ${ }^{-/-}$ and wild-type $(W t)$ mice from the same genetic background of either sex. Pregnant rats and mice were euthanized with $\mathrm{CO}_{2}$. Hippocampi and cortices were isolated as previously described (Seibenhener \& Wooten, 2012; Pierrot et al, 2013) with slight modifications. Briefly, hippocampal neurons were dissociated by incubation $\left(15 \mathrm{~min}, 37^{\circ} \mathrm{C}\right.$ ) in $0.25 \%$ Trypsin-EDTA and triturated in Hank's balanced salt solution without $\mathrm{CaCl}_{2}$ and $\mathrm{MgCl}_{2}$ supplemented with $10 \mathrm{mM}$ Hepes. Hippocampal and cortical cells were plated in culture dishes ( 1.5 and $4 \times 10^{5}$ cells $/ \mathrm{cm}^{2}$, respectively) pretreated with $10 \mu \mathrm{g} / \mathrm{ml}$ poly-L-lysine (Sigma-Aldrich) in PBS and cultured for 13-14 d in vitro in Neurobasal medium supplemented with $2 \%$ (vol/vol) B-27 medium and $0.5 \mathrm{mM}$ L-glutamine without antibiotic solution before analyses. Hippocampal cells were preplated in a neuronal plating medium (MEM with Earl's salt supplemented with 2 mM glutamine, $330 \mu$ M D-Glucose [Cat. No. G7528; Sigma-Aldrich], and 5\% fetal bovine serum [Cat. No. S1820; Biowest]) during 4-5 $\mathrm{h}$ before Neurobasal medium described above. The cultures were maintained at $37^{\circ} \mathrm{C}$ under a $5 \% \mathrm{CO}_{2}$ atmosphere and half of the medium was renewed every $2-3 \mathrm{~d}$.

\section{Recombinant viruses and infection}

Ppara and scramble shRNA containing AAV were purchased from Vectors Biolabs (Cat. No. shADV-269120 and 7045, respectively). For Ppara silencing, an AAV9-ShPpara $\left(3.9 \times 10^{13} \mathrm{GC} / \mathrm{ml}\right)$, containing an shRNA sequence (CCCTTATCTGAAGAATTCTTA) targeting both rat and mouse Ppara (Genbank RefSeq: NM_013196) and enhanced GFP (eGFP) reporter gene, was produced. The expressions of Ppara and
eGFP were driven by a U6 and a CMV promoter, respectively. An AAV9-GFP-U6-scramble shRNA (AAV-ShSc, $4.7 \times 10^{13} \mathrm{GC} / \mathrm{ml}$ ) was used as a control. Cultures were transduced on fourth day in vitro ( 4 DIV) using AAV-ShPpara or AAV-ShSc at a multiplicity of infection of 12,000 overnight. Then, the infection medium was replaced by a fresh culture medium every $2 \mathrm{~d}$ up to analysis (between 13 and 14 DIV).

\section{Treatments and oral gavage}

Treatments: cultured cells and hippocampal organotypic tissue cultures were treated for $24 \mathrm{~h}$ with $100 \mathrm{nM}$ and $300 \mathrm{nM}$ bexarotene in $0.0002 \%$ DMSO (Targretin), respectively. Control cells were treated with $0.0002 \%$ DMSO. For cell calcium imaging, neurons were challenged with $50 \mu \mathrm{M}$ NMDA (Cat. No. M3262; Sigma-Aldrich) or $50 \mu \mathrm{M}$ AMPA (Cat. No. 1074; Tocris) in the presence of $1 \mu \mathrm{M}$ tetrodotoxin, a selective inhibitor of $\mathrm{Na}^{+}$channel conductance used to block spontaneous $\left[\mathrm{Ca}^{2+}\right]_{\mathrm{i}}$ transients in neurons (Cat. No. 1078; Tocris). For LTP measurements done on acute hippocampal slices from transgenic 5xFAD mice (9-10 mo) injected with AAV-Sh constructs, slices were treated with $4 \mu \mathrm{M}$ bexarotene in artificial cerebrospinal fluid (aCSF) (see below) for 2 h30 min before high-frequency stimulation (see below).

Oral gavage: age-matched non-transgenic wild-type and 5xFAD mice (9-10 mo) were treated for $12 \mathrm{~d}$ by oral gavage with $100 \mathrm{mg} / \mathrm{kg} / \mathrm{d}$ b.wt. bexarotene or vehicle (water) or with $1 \mathrm{mg} / \mathrm{kg} / \mathrm{d}$ b.wt. pemafibrate (at 12 mo) (Hennuyer et al, 2016) (Cat. No. HY-17618; MedChemExpress) or vehicle (water 0.1\% Tween 80).

\section{Biotinylation and purification of plasma membrane-associated proteins}

13-14 DIV-cultured cells seeded at $4 \times 10^{5}$ cells $/ \mathrm{cm}^{2}$ were washed with Krebs-Hepes buffer (see below). The cells were incubated with $1.6 \mathrm{ml}$ of EZ-Link Sulfo-NHS-Biotin (Cat. No. 21217; Thermo Fisher Scientific) at $1.5 \mathrm{mg} / \mathrm{ml}$ in PBS for $30 \mathrm{~min}$ at $4^{\circ} \mathrm{C}$ with mild shaking. The cells were then washed twice with cold PBS containing $100 \mathrm{mM}$ glycine and incubated with the same solution for $45 \mathrm{~min}$ at $4^{\circ} \mathrm{C}$ to quench the unbound biotin reagent. The cells were solubilized in lysis buffer containing $25 \mathrm{mM}$ Tris- $\mathrm{HCl}$, pH 6.8, 0.5\% (vol/vol) Triton $\mathrm{X}-100$, and $0.5 \%$ ( vol/vol) Nonidet P-40 supplemented with proteases inhibitors for $1 \mathrm{~h}$ at $4^{\circ} \mathrm{C}$ with vigorous shaking. After centrifugation at $16,000 \mathrm{~g}$ at $4^{\circ} \mathrm{C}$ for $20 \mathrm{~min}, 300 \mu \mathrm{l}$ of supernatant were incubated with an equal volume of Pierce Streptavidin Agarose beads suspension (Cat. No. 20349; Thermo Fisher Scientific) for $1 \mathrm{~h}$ at room temperature. After centrifugation $\left(16,000 \mathrm{~g}, 15 \mathrm{~min}, 4^{\circ} \mathrm{C}\right.$ ), supernatants were collected for analysis of the non-biotinylated intracellular fraction. Biotinylated cell surface proteins contained in the pellet were washed two times with $600 \mu \mathrm{l}$ lysis buffer and two times in Krebs-Hepes buffer. The samples were eluted in $50 \mu \mathrm{l}$ loading buffer (see below), boiled at $95^{\circ} \mathrm{C}$ for $5 \mathrm{~min}$.

\section{Western blotting}

Cells in culture were washed, scraped off in PBS, and centrifuged for $2 \mathrm{~min}$ at 16,000 g. Pellets were sonicated in lysis buffer (125 mM Tris [pH 6.8], 20\% glycerol, and 4\% sodium dodecyl sulfate) with 
complete Protease Inhibitor Cocktail (Cat. No. 11697498001; Roche). For brain protein extraction, the samples were homogenized in RIPA buffer (1\% NP40, 0.5\% deoxycholic acid, 0.1\% SDS, $150 \mathrm{mM} \mathrm{NaCl}, 1 \mathrm{mM}$ EDTA, and $50 \mathrm{mM}$ Tris, pH 7.4) containing protease and phosphatase inhibitors cocktail (Cat. No. 04906837001; Roche). The samples were clarified by centrifugation at $20,000 \mathrm{~g}$, and the protein concentration was determined using a Bicinchoninic Acid Assay (BCA) kit. The samples were heated for $10 \mathrm{~min}$ at $70^{\circ} \mathrm{C}$ in loading buffer (lysis buffer containing 10\% 2-mercaptoethanol and 0.004\% bromophenol blue).

Cell and brain lysates ( 40 and $60 \mu \mathrm{g}$ of proteins, respectively) were analyzed by Western blotting using $4-12 \%$ Nupage bis-Tris gels. Nitrocellulose membranes were incubated overnight at $4^{\circ} \mathrm{C}$ with the following primary antibodies: anti-Glutamate Receptor 2 (GluA2, 1:1,000); anti-GluA1 (1:500); anti-GluN2A (1:250); anti-GluN2B (1:500); anti-ABCA1 (1:1,000); anti- $\alpha$ tubulin (1:4,000); and anti-Transf $\mathrm{R}(1: 1,000)$. Blots were incubated with HRP peroxidase-conjugated secondary antibodies (1:10,000), revealed by ECL (Cat. No. ORT26552755; Amersham Pharmacia), and quantified using the Quantity One software (Bio-Rad Laboratories). $\alpha$-tubulin or Transf R was used as internal standards to normalize protein load in gels.

\section{RNA extraction and real-time PCR}

Total RNA was isolated by TriPure Isolation Reagent (Cat. No. 11667165001; Roche) according to the manufacturer's protocol. RNA samples were resuspended in DEPC-treated water. Reverse transcription was carried out with the iscript cDNA synthesis kit (Cat. No. 1708891; Bio-Rad Laboratories) using $1 \mu \mathrm{g}$ of total RNA in a total volume reaction of $20 \mu \mathrm{l}$. Real-time PCR was performed for the amplification of cDNAs with specific primers (Sigma-Aldrich, see Table S1).

Real-time PCR was carried out in a total volume of $25 \mu \mathrm{l}$ containing $8 \mathrm{ng}$ CDNA template, $0.3 \mu \mathrm{M}$ of the appropriate primers, and the IQ SYBR Green Supermix 1× (Cat. No. 1708885; Bio-Rad Laboratories). The PCR protocol consisted of 40 amplification cycles $\left(95^{\circ} \mathrm{C}\right.$ for $30 \mathrm{~s}, 60^{\circ} \mathrm{C}$ for $45 \mathrm{~s}$, and $79^{\circ} \mathrm{C}$ for $15 \mathrm{~s}$ ) and was performed using an iCycler IQ Multicolor Real-Time PCR Detection System (BioRad Laboratories), to determine the threshold cycle (Ct). Melting curves were performed to detect nonspecific amplification products. A standard curve was established for each target gene using fourfold serial dilutions (from 100 to $0.097 \mathrm{ng}$ ) of a cDNA template mix prepared in the same conditions. The differences between the Ct of one condition and the control were measured, and each sample was normalized with the relative expression levels of Gapdh.

\section{Cytosolic-free $\mathrm{Ca}^{2+}$ measurement in single neurons}

For cytosolic-free $\mathrm{Ca}^{2+}$ measurement, all recordings were carried out at $37^{\circ} \mathrm{C}$ in Krebs-Hepes buffer (10 mM Hepes, $135 \mathrm{mM} \mathrm{NaCl}, 6 \mathrm{mM}$ $\mathrm{KCl}, 2 \mathrm{mM} \mathrm{CaCl}, 1.2 \mathrm{mM} \mathrm{MgCl}$, and $10 \mathrm{mM}$ glucose, $\mathrm{pH} 7.4)$, as previously described (Doshina et al, 2017). Briefly, $50 \mu \mathrm{M}$ NMDA or AMPA were perfused with Krebs-Hepes buffer in the incubation chamber. Neurons were plated at a density of $1.8 \times 10^{5}$ cells $/ \mathrm{cm}^{2}$ on $15-\mathrm{mm}$ round glass coverslips precoated with $10 \mu \mathrm{g} / \mathrm{ml}$ poly-Llysine in PBS. 13-14 DIV-cultured cells were incubated in the dark in the presence of the $\mathrm{Ca}^{2+}$ indicator fura-2 acetoxymethylester (Fura2 AM; Cat. No. F1225) at a final concentration of $2 \mu \mathrm{M}$ in Krebs-Hepes buffer for $30 \mathrm{~min}$ at room temperature. Coverslips were then washed and mounted in a heated $\left(37^{\circ} \mathrm{C}\right)$ microscope chamber $(1 \mathrm{ml})$. The cells were alternately excited (1 or $2 \mathrm{~Hz}$ ) at 340 and 380 nm for 100 ms using a Lambda DG-4 Ultra High Speed Wavelength Switcher (Sutter Instrument) coupled to a Zeiss Axiovert $200 \mathrm{M}$ inverted microscope (X20 fluorescence objective) (Zeiss Belgium). Images were acquired using a Zeiss Axiocam camera coupled to a 510-nm emission filter and analyzed with Axiovision software. A total of 70-80 neurons were studied in each experiment, and non-neuronal cells were excluded from the analysis as previously described by Pickering and coworkers (Pickering et al, 2008). Changes in intracellular calcium fluorescence were estimated from fluorescence emission intensity ratio F340/F380 ( $\Delta \mathrm{F}$ ) obtained after excitation of cells at wavelengths of 340 and $380 \mathrm{~nm}$. These changes were expressed as normalized fluorescence where every measurement of $\Delta F$ was divided by the basal fluorescence (F0) value corresponding to the mean of signals measured during a period of $20 \mathrm{~s}$ in basal condition (before NMDA or AMPA). NMDA and AMPA responses were defined as a change of $\triangle F$ greater than $10 \%$ relative to FO.

\section{Stereotaxic injections}

For stereotaxic surgery, 9-10-mo-old 5xFAD mice were anesthetized by intraperitoneal injection (i.p.) with a mixture of $160 \mathrm{mg} / \mathrm{kg}$ b.wt. ketamine (Nimatek; Eurovet Animal Health BV) and $20 \mathrm{mg} / \mathrm{kg}$ b.wt. xylazine (ROMPUN; Bayer). Ipsi and contralateral stereotaxic injections (left and right hemisphere, respectively) were performed at two sites in the hippocampal CA1 region ( $A / P,-1.8 ; L, \pm 1.1 ; D / V,-1.3$ and $A / P,-2.5 ; \mathrm{L}, \pm 2.0 ; \mathrm{D} / \mathrm{V},-1.5)$ millimeter relative to bregma (Paxinos \& Franklin, 2001). I psilateral AAV-ShPpara $\left(3.9 \times 10^{13} \mathrm{GC} / \mathrm{ml}\right)$ or contralateral AAV-ShSC $\left(4.7 \times 10^{13} \mathrm{GC} / \mathrm{ml}\right)$ stereotaxic injection ( $5 \mu \mathrm{l}$ in total of each; $2.5 \mu \mathrm{l}$ per site of injections) were performed using a 10- $\mu$ l Hamilton syringe (Filter Service, Cat. No. HA 7635-01) at a speed of $1 \mu \mathrm{l}$ per min. After injection, the needle was kept in place for additional 3 min before gentle withdrawal. All analyses were performed 3 wk postinjection.

\section{Electrophysiology-LTP}

Male and female PPAR $\alpha$-deficient $\left(\mathrm{Ppara}^{-/-}\right.$) and transgenic (Tg) 5XFAD mice at 5-6 and 9-10 mo of age, respectively, were anesthetized with pentobarbital (Nembutal, i.p. $100 \mathrm{mg} / \mathrm{kg}$ b.wt.) and decapitated. Age-matched wild-type (Wt) mice of the same genetic background were used as controls. The hippocampus was dissected and cut into 450- $\mu$ m-thick slices with a tissue chopper. The slices were transferred into the recording chamber and kept in interface at $28^{\circ} \mathrm{C}$ for $1.5 \mathrm{~h}$. Hippocampal slices were perfused with aCSF with the following composition: $124 \mathrm{mM} \mathrm{NaCl}, 5 \mathrm{mM} \mathrm{KCl}, 26 \mathrm{mM} \mathrm{NaHCO}_{3}$, $1.24 \mathrm{mM} \mathrm{NaH}_{2} \mathrm{PO}_{4}, 2.5 \mathrm{mM} \mathrm{CaCl}_{2}, 1.3 \mathrm{mM} \mathrm{MgSO}_{4}$, and $10 \mathrm{mM}$ glucose, bubbled with a mixture of $95 \% \mathrm{O}_{2}$ and $5 \% \mathrm{CO}_{2}$. The perfusion rate of aCSF was $1 \mathrm{ml} / \mathrm{min}$. LTP was induced by applying one train $(100 \mathrm{~Hz}, 1$ s). A bipolar twisted nickel-chrome electrode (50 $\mu \mathrm{m}$ each) was used to stimulate Schaffer's collaterals. Extracellular field excitatory postsynaptic potentials (fEPSPS) were recorded in the stratum 
radiatum of the CA1 region with low-resistance (2-5 M $\Omega$ ) glass microelectrodes filled with aCSF (Villers \& Ris, 2013). Test stimuli were biphasic (0.08 ms for each pulse) constant-voltage pulses delivered every minute with an intensity adjusted to evoke an approximate $40 \%$ maximal response. The slope of the fEPSP was measured on the average of four consecutive responses. Stimulation, data acquisition, and analysis were performed using the WinLTP program (Anderson \& Collingridge, 2007) (www.winltp.com). For each slice, the fEPSP slopes were normalized with respect to the mean slope of the fEPSPS recorded during the 30-min period preceding induction of LTP.

\section{Confocal microscopy and image processing and analysis}

Cells were seeded at $10^{5}$ cells $/ \mathrm{cm}^{2}$ on $15-\mathrm{mm}$ round glass coverslips precoated with $10 \mu \mathrm{g} / \mathrm{ml}$ poly-L-lysine in PBS, fixed 15 min with $4 \%$ $\mathrm{vol} / \mathrm{vol}$ formaldehyde at room temperature, then washed in PBS, and permeabilized $1 \mathrm{~h}$ with $0.4 \%$ Triton $\mathrm{X}-100$ (vol/vol) in PBS containing 3\% bovine serum albumin (Cat. No. A7906; SigmaAldrich). After three washes in PBS, the cells were incubated $1 \mathrm{~h}$ at room temperature with primary antibodies: anti-SynGAP (1:50), anti-MAP2 (1:1,000), and anti-GluA1 (1:100). After three PBS washes, the cells were incubated for $1 \mathrm{~h}$ with $5 \mu \mathrm{g} / \mathrm{ml}$ Alexa-labelled secondary antibodies (1:200). After three additional PBS washes, preparations were mounted in EverBrite (Cat. No. 23003; VWR) and were examined with an LSM 510 META confocal microscope (Zeiss) using a Plan-Apochromat $63 \times / 1.4$ oil DIC objective. The nonoverlapping between GluA1 and SynGAP was determined on line intensity profiles. After threshold value determination to define the effective dynamic range, peaks were identified and classified into three categories: (i) only red, indicating non-overlapping of GluA1 with SynGAP; (ii) only green, indicating non-overlapping of SynGAP with GluA1; and (iii) red + green, indicating overlapping between GluA1 and SynGAP. The abundance of peaks in each category was then expressed as percentage of total peaks. Cluster size of GluA1 puncta was quantified using Axiovision 4.8.2. Images were first resampled to isolate the red channel for analysis (resampling step) and then segmented to isolate only the grey values between 80 and 255 (segmentation step). Images were then binarized, with the white areas corresponding to the GluA1 clusters (binary scrap step), and small holes in these clusters were filled up (binary fill step). After visual comparison of these white areas with the clusters on the initial pictures, the average area of clusters was measured with the AxioVision software in the "automatic measurement" mode, and data were exported in Excel for calculation and statistical analysis.

\section{Statistics}

Statistical analyses were performed using GraphPad Prism 7.01 (GraphPad Software). The Shapiro-Wilk test was used to test for the normality of data. Parametric testing procedures ( $t$ test or one-way analysis of variance [ANOVA] followed by Bonferroni's multiplecomparison posttest when many subgroups were compared) were applied for normally distributed data, otherwise nonparametric tests were used (Mann-Whitney or Kruskal-Wallis tests followed by Dunn's multiple-comparison posttest when many subgroups were compared). Total number of samples ( $n$ ) analyzed in all experimental conditions (number of repeated measurements) is indicated in figures legends. Results were presented as mean \pm SEM and statistical significance was set at $P$ values $<0.05$ (two-tailed tests, except for Morris water maze experiments, only a one-sided $P$ value is presented) $\left({ }^{\star} P<0.05,{ }^{*} P<0.01 ;{ }^{* \star} P<0.001\right)$. For LTP, statistical differences of the means $( \pm$ SEM) were measured on the last $30 \mathrm{~min}$ before the end of the recording. Graphical data are represented as plot data with individual points overlaid (Supplemental Data 1).

\section{Supplementary Information}

Supplementary Information is available at https://doi.org/10.26508/lsa. 201800262

\section{Acknowledgements}

We thank the Fondation Louvain for support to N Pierrot; the Netherlands Brain Bank for providing us with human brain samples; F Saez-Orellana, PhD (IoNS, Brussels, Belgium), for discussion; and Pr. L Hue for his critical evaluation of the results and editing the manuscript. This work was supported by the Belgian Fonds pour la Recherche Scientifique, Interuniversity Attraction Poles Program-Belgian State-Belgian Science Policy, The Belgian Fonds de la Recherche Scientifique Médicale, the Queen Elisabeth Medical Foundation, and the Fondation pour la Recherche sur la Maladie d'Alzheimer.

\section{Author Contributions}

N Pierrot: conceptualization, formal analysis, supervision, validation, investigation, methodology, and writing-original draft, review, and editing.

L Ris: formal analysis and methodology.

I-C Stancu: methodology.

A Doshina: methodology.

F Ribeiro: methodology.

D Tyteca: methodology and writing-original draft.

E Baugé: methodology.

F Lalloyer: methodology.

L Malong: methodology.

o schakman: methodology.

K Leroy: methodology.

P Kienlen-Campard: project administration.

P Gailly: methodology and writing-original draft.

J-P Brion: methodology.

I Dewachter: methodology.

B Staels: conceptualization, methodology, and writing-original draft.

J-N Octave: conceptualization, formal analysis, supervision, funding acquisition, validation, investigation, and writing-original draft, review, and editing.

\section{Conflict of Interest Statement}

The authors declare that they have no conflict of interest. 


\section{References}

Anderson WW, Collingridge GL (2007) Capabilities of the WinLTP data acquisition program extending beyond basic LTP experimental functions. J Neurosci Methods 162: 346-356. doi:10.1016/j. jneumeth.2006.12.018

Araki E, Yamashita S, Arai H, Yokote K, Satoh J, Inoguchi T, Nakamura J, Maegawa H, Yoshioka N, Tanizawa Y, et al (2018) Effects of pemafibrate, a novel selective PPARalpha modulator, on lipid and glucose metabolism in patients with type 2 diabetes and hypertriglyceridemia: A randomized, double-blind, placebocontrolled, phase 3 trial. Diabetes Care 41: 538-546. doi:10.2337/dc171589

Arevalo MA, Azcoitia I, Gonzalez-Burgos I, Garcia-Segura LM (2015) Signaling mechanisms mediating the regulation of synaptic plasticity and memory by estradiol. Horm Behav 74: 19-27. doi:10.1016/j. yhbeh.2015.04.016

Barrier L, Ingrand S, Fauconneau B, Page G (2010) Gender-dependent accumulation of ceramides in the cerebral cortex of the APP(SL)/ PS1Ki mouse model of Alzheimer's disease. Neurobiol Aging 31: 1843-1853. doi:10.1016/j.neurobiolaging.2008.10.011

Bensinger SJ, Tontonoz P (2008) Integration of metabolism and inflammation by lipid-activated nuclear receptors. Nature 454: 470-477. doi:10.1038/ nature07202

Bliss TV, Collingridge GL (1993) A synaptic model of memory: Long-term potentiation in the hippocampus. Nature 361: 31-39. doi:10.1038/ $361031 \mathrm{a} 0$

Bookout AL, Jeong Y, Downes M, Yu RT, Evans RM, Mangelsdorf DJ (2006) Anatomical profiling of nuclear receptor expression reveals a hierarchical transcriptional network. Cell 126: 789-799. doi:10.1016/j. cell.2006.06.049

Chen HJ, Rojas-Soto M, Oguni A, Kennedy MB (1998) A synaptic Ras-GTPase activating protein (p135 SynGAP) inhibited by CaM kinase II. Neuron 20: 895-904. doi:10.1016/s0896-6273(00)80471-7

Chung KW, Lee EK, Lee MK, Oh GT, Yu BP, Chung HY (2018) Impairment of PPARalpha and the fatty acid oxidation pathway aggravates renal fibrosis during aging. I Am Soc Nephrol 29: 1223-1237. doi:10.1681/ asn.2017070802

Corbett GT, Gonzalez FJ, Pahan K (2015) Activation of peroxisome proliferatoractivated receptor alpha stimulates ADAM10-mediated proteolysis of APP. Proc Natl Acad Sci U S A 112: 8445-8450. doi:10.1073/ pnas. 1504890112

D’Agostino G, Cristiano C, Lyons DJ, Citraro R, Russo E, Avagliano C, Russo R, Raso GM, Meli R, De SG, et al (2015) Peroxisome proliferator-activated receptor alpha plays a crucial role in behavioral repetition and cognitive flexibility in mice. Mol Metab 4: 528-536. doi:10.1016/j. molmet.2015.04.005

D'Orio B, Fracassi A, Ceru MP, Moreno S (2018) Targeting PPARalpha in Alzheimer's disease. Curr Alzheimer Res 15: 345-354. doi:10.2174/ 1567205014666170505094549

Derkach VA, Oh MC, Guire ES, Soderling TR (2007) Regulatory mechanisms of AMPA receptors in synaptic plasticity. Nat Rev Neurosci 8: 101-113. doi:10.1038/nrn2055

Doshina A, Gourgue F, Onizuka M, Opsomer R, Wang P, Ando K, Tasiaux B, Dewachter I, Kienlen-Campard P, Brion JP, et al (2017) Cortical cells reveal APP as a new player in the regulation of GABAergic neurotransmission. Sci Rep 7: 370. doi:10.1038/s41598-017-00325-2

Dotson AL, Wang J, Chen Y, Manning D, Nguyen H, Saugstad JA, Offner H (2016) Sex differences and the role of PPAR alpha in experimental stroke. Metab Brain Dis 31: 539-547. doi:10.1007/s11011-015-9766-X

Dowell P, Ishmael JE, Avram D, Peterson VJ, Nevrivy DJ, Leid M (1997) p300 functions as a coactivator for the peroxisome proliferator-activated receptor alpha. J Biol Chem 272: 33435-33443. doi:10.1074/ jbc.272.52.33435

Evans RM, Mangelsdorf DJ (2014) Nuclear receptors, RXR, and the Big Bang. Cell 157: 255-266. doi:10.1016/j.cell.2014.03.012

Ferretti MT, Iulita MF, Cavedo E, Chiesa PA, Schumacher DA, Santuccione CA, Baracchi F, Girouard H, Misoch S, Giacobini E, et al (2018) Sex differences in Alzheimer disease: The gateway to precision medicine. Nat Rev Neurol 14: 457-469. doi:10.1038/s41582-018-0032-9

Gross B, Pawlak M, Lefebvre P, Staels B (2017) PPARs in obesity-induced T2DM, dyslipidaemia and NAFLD. Nat Rev Endocrinol 13: 36-49. doi:10.1038/ nrendo.2016.135

Hennuyer N, Duplan I, Paquet C, Vanhoutte J, Woitrain E, Touche V, Colin S, Vallez E, Lestavel S, Lefebvre P, et al (2016) The novel selective PPARalpha modulator (SPPARMalpha) pemafibrate improves dyslipidemia, enhances reverse cholesterol transport and decreases inflammation and atherosclerosis. Atherosclerosis 249: 200-208. doi:10.1016/j.atherosclerosis.2016.03.003

Ishibashi S, Arai H, Yokote K, Araki E, Suganami H, Yamashita S (2018) Efficacy and safety of pemafibrate (K-877), a selective peroxisome proliferator-activated receptor alpha modulator, in patients with dyslipidemia: Results from a 24-week, randomized, double blind, active-controlled, phase 3 trial. J Clin Lipidol 12: 173-184. doi:10.1016/j. jacl.2017.10.006

Jalouli M, Carlsson L, Ameen C, Linden D, Ljungberg A, Michalik L, Eden S, Wahli W, Oscarsson J (2003) Sex difference in hepatic peroxisome proliferator-activated receptor alpha expression: Influence of pituitary and gonadal hormones. Endocrinology 144: 101-109. doi:10.1210/en.2002-220630

Lalloyer F, Wouters K, Baron M, Caron S, Vallez E, Vanhoutte J, Bauge E, ShiriSverdlov R, Hofker M, Staels B, et al (2011) Peroxisome proliferatoractivated receptor-alpha gene level differently affects lipid metabolism and inflammation in apolipoprotein E2 knock-in mice. Arterioscler Thromb Vasc Biol 31: 1573-1579. doi:10.1161/ atvbaha.110.220525

Lee SS, Pineau T, Drago J, Lee EJ, Owens JW, Kroetz DL, Fernandez-Salguero PM, Westphal H, Gonzalez FJ (1995) Targeted disruption of the alpha isoform of the peroxisome proliferator-activated receptor gene in mice results in abolishment of the pleiotropic effects of peroxisome proliferators. Mol Cell Biol 15: 3012-3022. doi:10.1128/mcb.15.6.3012

Lefebvre P, Benomar Y, Staels B (2010) Retinoid X receptors: Common heterodimerization partners with distinct functions. Trends Endocrinol Metab 21: 676-683. doi:10.1016/j.tem.2010.06.009

Mariani MM, Malm T, Lamb R, Jay TR, Neilson L, Casali B, Medarametla L, Landreth GE (2017) Neuronally-directed effects of RXR activation in a mouse model of Alzheimer's disease. Sci Rep 7: 42270. doi:10.1038/ srep 42270

Middei S, Houeland G, Cavallucci V, Ammassari-Teule M, D'Amelio M, Marie H (2013) CREB is necessary for synaptic maintenance and learninginduced changes of the AMPA receptor GluA1 subunit. Hippocampus 23: 488-499. doi:10.1002/hipo.22108

Montagne A, Zhao Z, Zlokovic BV (2017) Alzheimer's disease: A matter of blood-brain barrier dysfunction? J Exp Med 214: 3151-3169. doi:10.1084/jem.20171406

Mounier A, Georgiev D, Nam KN, Fitz NF, Castranio EL, Wolfe CM, Cronican AA, Schug J, Lefterov I, Koldamova R (2015) Bexarotene-activated retinoid $X$ receptors regulate neuronal differentiation and dendritic complexity. J Neurosci 35: 11862-11876. doi:10.1523/jneurosci.100115.2015

Moutinho M, Landreth GE (2017) Therapeutic potential of nuclear receptor agonists in Alzheimer's disease. J Lipid Res 58: 1937-1949. doi:10.1194/ jlr.r075556

Nam KN, Mounier A, Fitz NF, Wolfe C, Schug J, Lefterov I, Koldamova R (2016) RXR controlled regulatory networks identified in mouse brain 
counteract deleterious effects of Abeta oligomers. Sci Rep 6: 24048. doi:10.1038/srep24048

Oakley H, Cole SL, Logan S, Maus E, Shao P, Craft J, Guillozet-Bongaarts A, Ohno M, Disterhoft J, Van EL, et al (2006) Intraneuronal beta-amyloid aggregates, neurodegeneration, and neuron loss in transgenic mice with five familial Alzheimer's disease mutations: Potential factors in amyloid plaque formation. J Neurosci 26: 10129-10140. doi:10.1523/ jneurosci.1202-06.2006

Paxinos G, Franklin KBJ (2001) The Mouse Brain in Stereotaxic Coordinates. San Diego, CA: Academic

Perez E, Bourguet W, Gronemeyer H, de Lera AR (2012) Modulation of RXR function through ligand design. Biochim Biophys Acta 1821: 57-69. doi:10.1016/j.bbalip.2011.04.003

Pickering M, Pickering BW, Murphy KJ, O'Connor JJ (2008) Discrimination of cell types in mixed cortical culture using calcium imaging: A comparison to immunocytochemical labeling. J Neurosci Methods 173: 27-33. doi:10.1016/j.jneumeth.2008.05.014

Pierrot N, Lhommel R, Quenon L, Hanseeuw B, Dricot L, Sindic C, Maloteaux JM, Octavea JN, Ivanoiu A (2016) Targretin improves cognitive and biological markers in a patient with Alzheimer's disease. J Alzheimers Dis 49: 271-276. doi:10.3233/JAD-150405

Pierrot N, Tyteca D, D'auria L, Dewachter I, Gailly P, Hendrickx A, Tasiaux B, Haylani LE, Muls N, N'kuli F, et al (2013) Amyloid precursor protein controls cholesterol turnover needed for neuronal activity. EMBO Mol Med 5: 608-625. doi:10.1002/emmm.201202215

Raza-Iqbal S, Tanaka T, Anai M, Inagaki T, Matsumura Y, Ikeda K, Taguchi A, Gonzalez FJ, Sakai J, Kodama T (2015) Transcriptome analysis of K-877 (a novel selective PPARalpha modulator (SPPARMalpha))-regulated genes in primary human hepatocytes and the mouse liver. J Atheroscler Thromb 22: 754-772. doi:10.5551/jat.28720

Riecher-Rossler A (2017) Sex and gender differences in mental disorders. Lancet Psychiatry 4: 8-9. doi:10.1016/s2215-0366(16)30348-0

Roy A, Jana M, Corbett GT, Ramaswamy S, Kordower JH, Gonzalez FJ, Pahan K (2013) Regulation of cyclic AMP response element binding and hippocampal plasticity-related genes by peroxisome proliferatoractivated receptor alpha. Cell Rep 4: 724-737. doi:10.1016/j. celrep.2013.07.028

Schmitt WB, Sprengel R, Mack V, Draft RW, Seeburg PH, Deacon RM, Rawlins JN, Bannerman DM (2005) Restoration of spatial working memory by genetic rescue of GluR-A-deficient mice. Nat Neurosci 8: 270-272. doi:10.1038/nn1412
Schulman IG, Shao G, Heyman RA (1998) Transactivation by retinoid X receptor-peroxisome proliferator-activated receptor gamma (PPARgamma) heterodimers: Intermolecular synergy requires only the PPARgamma hormone-dependent activation function. Mol Cell Biol 18: 3483-3494. doi:10.1128/mcb.18.6.3483

Seibenhener ML, Wooten MW (2012) Isolation and culture of hippocampal neurons from prenatal mice. J Vis Exp 3634. doi:10.3791/3634

Staels B, Dallongeville J, Auwerx J, Schoonjans K, Leitersdorf E, Fruchart JC (1998) Mechanism of action of fibrates on lipid and lipoprotein metabolism. Circulation 98: 2088-2093. doi:10.1161/01.cir.98.19.2088

Tata JR (1994) Autoregulation and crossregulation of nuclear receptor genes. Trends Endocrinol Metab 5: 283-290. doi:10.1016/1043-2760(94)p3203-j

Venkateswaran A, Laffitte BA, Joseph SB, Mak PA, Wilpitz DC, Edwards PA, Tontonoz P (2000) Control of cellular cholesterol efflux by the nuclear oxysterol receptor LXR alpha. Proc Natl Acad Sci U S A 97: 12097-12102. doi:10.1073/pnas.200367697

Villers A, Ris L (2013) Improved preparation and preservation of hippocampal mouse slices for a very stable and reproducible recording of longterm potentiation. J Vis Exp doi:10.3791/50483

Warden A, Truitt J, Merriman M, Ponomareva O, Jameson K, Ferguson LB, Mayfield RD, Harris RA (2016) Localization of PPAR isotypes in the adult mouse and human brain. Sci Rep 6: 27618. doi:10.1038/srep27618

Watt MJ, Southgate RJ, Holmes AG, Febbraio MA (2004) Suppression of plasma free fatty acids upregulates peroxisome proliferator-activated receptor (PPAR) alpha and delta and PPAR coactivator 1alpha in human skeletal muscle, but not lipid regulatory genes. I Mol Endocrinol 33: 533-544. doi:10.1677/jme.1.01499

Yamazaki Y, Abe K, Toma T, Nishikawa M, Ozawa H, Okuda A, Araki T, Oda S, Inoue K, Shibuya K, et al (2007) Design and synthesis of highly potent and selective human peroxisome proliferator-activated receptor alpha agonists. Bioorg Med Chem Lett 17: 4689-4693. doi:10.1016/j. bmcl.2007.05.066

Zolezzi JM, Santos MJ, Bastias-Candia S, Pinto C, Godoy JA, Inestrosa NC (2017) PPARs in the central nervous system: Roles in neurodegeneration and neuroinflammation. Biol Rev Camb Philos Soc 92: 2046-2069. doi:10.1111/brv.12320

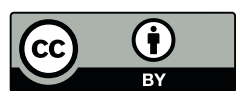

License: This article is available under a Creative Commons License (Attribution 4.0 International, as described at https://creativecommons.org/ licenses/by/4.0/). 